\title{
Analysis of tunnel excavation in London Clay incorporating soil structure
}

\author{
N. A. GONZÁlez*, M. ROUAINIA†, M. ARROYO* and A. GENS*
}

Recent studies on London Clay have identified a number of different units in the geological profile, and have highlighted the role of soil structure in mechanical behaviour. In fact, structure is the dominant factor determining the differences in the mechanical response of different units. In the paper, numerical analyses simulating the undrained excavation of a tunnel in St James's Park are presented. London Clay behaviour is characterised by a kinematic-hardening structured soil model incorporating structure and stiffness degradation. The parameters and initial conditions are based on a careful calibration that takes into account the presence of different units within the London Clay formation and the different degrees of soil structure. The analyses performed result in a very satisfactory reproduction of the magnitude and patterns of short-term surface and subsurface displacements, as well as pore pressures. The paper concludes with a discussion of the results in the context of other analyses performed previously, and puts forward some considerations concerning design issues.

KEYWORDS: fabric/structure of soils; ground movements; numerical modelling; tunnels
Des études récentes sur l'argile de Londres ont permis d'identifier un certain nombre d'unités diverses du profil géologique, et souligné le rôle de la structure du sol sur le comportement mécanique. En fait, la structure est le facteur dominant qui détermine les différences dans la réponse mécanique des différentes unités. Cette communication présente des analyses numériques simulant l'excavation non drainée d'un tunnel réalisé dans le parc $S t$ James's Park, à Londres. Le comportement de l'argile de Londres est caractérisé par un modèle de sol structuré cinématique /à durcissement, incorporant une dégradation de la structure et de la rigidité. Les paramètres et les conditions initiales sont basés sur un calibrage attentif tenant compte de la présence de différentes unités au sein de la formation d'argile de Londres, et des différents degrés de structure du sol. Les analyses effectuées permettent d'obtenir une reproduction très satisfaisante de la magnitude et des configurations de déplacements à court terme à la surface et souterrains, ainsi que des pressions interstitielles. La communication se termine par une discussions des résultats dans le contexte d'autres analyses effectuées précédemment, et avance certaines considérations relatives à des problèmes d'étude.

\section{INTRODUCTION}

It is now commonly accepted that the mechanical response of most saturated natural clays is dependent not just on stress and density, but also on structure. Structure is the result of depositional and post-depositional processes that are not reproduced when reconsolidating clay from slurry in the laboratory. Structure endows natural clays with higher strength and a more fragile response than their reconstituted counterparts. In most cases it does also increase their stiffness. Experimental evidence for important structurerelated effects in clay was initially gathered from relatively soft, sensitive clays (e.g. Champlain clay, Wong \& Mitchell, 1975; Bothkennar clay, Smith et al., 1992). Later it was also made evident in overconsolidated, stiff clays (Cotecchia \& Chandler, 1997).

The important effects of structure in the stiff overconsolidated London Clay were already pointed out by Burland (1990). More recently, prompted by the Heathrow Terminal 5 (T5) project, a systematic experimental effort was directed to ascertain the effect of structure in London Clay (Hight et al., 2007; Gasparre et al., 2007a; Gasparre \& Coop, 2008). The structure of natural London Clay, it was noted, enhanced peak intact strengths, increased bulk stiffness and, somewhat surprisingly, showed neutral or negative effects on shear stiffness. In the oedometer, as expected, the structured natural clay sustained higher stresses at similar void ratios than the reconstituted clay but, on the other hand, it did not

Manuscript received 22 March 2011; revised manuscript accepted 21 March 2012. Published online ahead of print 22 August 2012.

Discussion on this paper closes on 1 May 2013, for further details see p. ii.

* Departamento de Ingeniería del Terreno, UPC, Barcelona, Spain.

$\uparrow$ School of Civil Engineering \& Geosciences, Newcastle University, UK. show clearly marked yield points. This work also benefited from recently improved knowledge about the stratigraphy of the London Clay (de Freitas \& Mannion, 2007). The results were then ordered, taking into account the relevant sub-units of the London Clay formation. It is thus logical to expect that a proper understanding of geotechnical activities in London Clay should incorporate structure in the constitutive description of the soil in the context of the known geological profile of the material.

To explore that proposition, the case selected here is that of the westbound tunnel of the Jubilee Line Extension beneath St James's Park in central London. This is a welldocumented case (Standing \& Burland, 2006) that has attracted the attention of several researchers (e.g. Addenbrooke et al., 1997; Franzius et al., 2005; Wongsaroj et al., 2007; Grammatikopoulou et al., 2008). None of these previous analyses employed a model incorporating structure, or considered explicitly the detailed geological profile of the London Clay. Hence it seemed appropriate to explore the influence of these features in the problem.

Constitutive models including a measure of structure are well established (e.g. Kavvaddas \& Amorosi, 2000; Baudet \& Stallebrass, 2004), but there is limited experience in the application of such models to boundary value problems (Karstunen et al., 2005; Panayides \& Rouainia, 2010). This is largely due to difficulties in initialising the structure field for natural soil deposits. To measure initial structure, extensive high-quality laboratory campaigns are currently the only clear option. In situ testing offers an interesting alternative, but non-conventional procedures are necessary to separate structure from other factors affecting the result (González et al., 2009).

In this study, laboratory tests on natural London Clay presented by Hight et al. (2007) are employed to calibrate a structured kinematic-hardening soil model based on Rouainia 
\& Wood (2000), taking into account the different sub-units of London Clay. A tentative structure profile is thus derived for the T5 site and later applied to simulate the St James's case. The results obtained are discussed in the context of other analyses of the same case, and some design implications of incorporating structure in the analysis are finally presented.

\section{MATERIAL MODEL}

The constitutive model employed in this study is close to the one described by Rouainia \& Wood (2000). This section focuses on the modifications introduced in the original formulation. For completeness, full model equations are presented in the Appendix.

The model contains three surfaces in stress space: a kinematic yield surface (bubble $f_{\mathrm{b}}$ ), a structure surface $(F)$ and a reference surface $\left(f_{\mathrm{r}}\right)$, as shown in Fig. 1. The bubble surface separates the elastic response from the elasto-plastic response, and the structure surface position defines the current structure magnitude (isotropy of structure is assumed here for simplicity). Structure decreases with plastic strain, and the structure surface reduces to the reference surface, which defines the behaviour of the non-structured or reconstituted material. All three surfaces change in size whenever any plastic volumetric strain occurs. Note that, in the following, the term 'intrinsic preconsolidation pressure' refers to $2 P_{\mathrm{c}}$ in Fig. 1, and 'equivalent preconsolidation pressure' refers to $2 P_{\mathrm{c}} r$.

The original formulation for the hardening modulus at the current stress, $H$, does not predict a smooth transition from

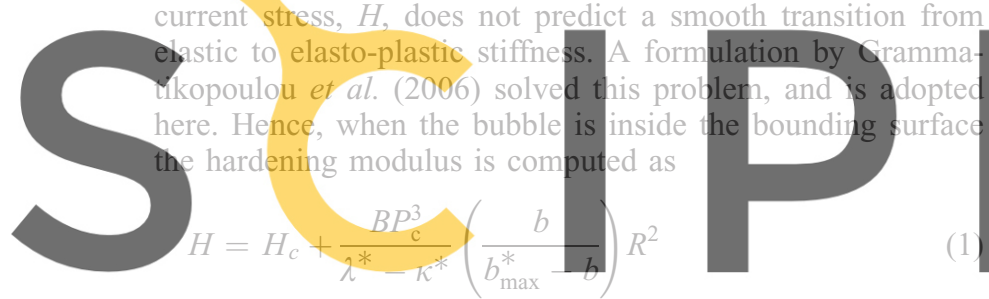

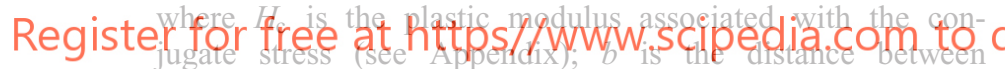
current stress and conjugate stress; $B$ is a parameter that controls the rate of decay of stiffness with strain: $\kappa^{*}=\kappa /(1+e)$ are the slopes of the isotropic compression and swelling lines (in $\ln e-\ln p$ space); and $e$ is the void ratio. The value of $b_{\max }^{*}$ is set equal to the value of $b$ when the stress state first becomes elasto-plastic (i.e. engages the kinematic yield surface). For any subsequent stage the value of $b_{\max }^{*}$ is incrementally updated to account for the change in size of the outer surface. The formulation of Grammati-

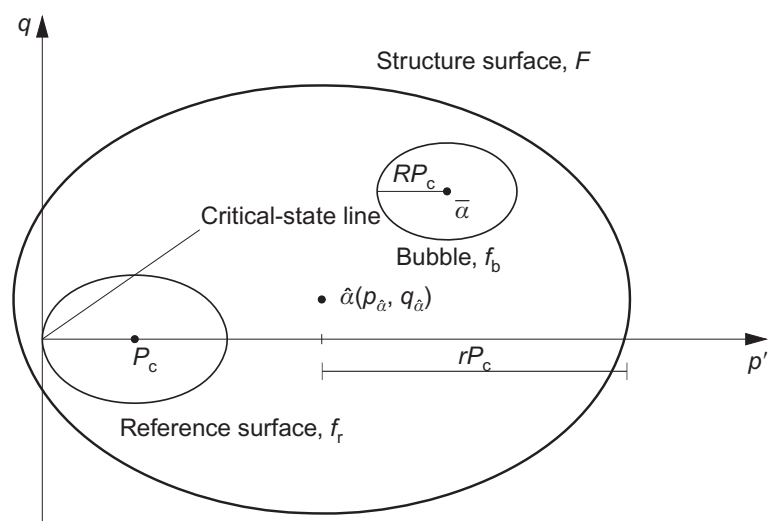

Fig. 1. Rouainia \& Wood (2000) constitutive model kopoulou et al. (2006) is thus adapted to account for the presence of structure in the model (González, 2011).

The formulation for small-strain stiffness also differs from Rouainia \& Wood (2000). The empirical proposal by Viggiani \& Atkinson (1995) is employed here

$$
\frac{G}{p_{\mathrm{r}}}=A_{\mathrm{g}}\left(\frac{p^{\prime}}{p_{\mathrm{r}}}\right)^{n_{\mathrm{g}}} R_{\mathrm{o}}^{m_{\mathrm{g}}}
$$

where $A_{\mathrm{g}}, n_{\mathrm{g}}$ and $m_{\mathrm{g}}$ are dimensionless parameters; $p_{\mathrm{r}}$ is a reference pressure $(1 \mathrm{kPa})$; and $R_{\mathrm{o}}=2 P_{\mathrm{c}} / p^{\prime}$, is the isotropic overconsolidation.

\section{APPLICATION TO LONDON CLAY \\ Summary of previous findings}

A combination of biostratigraphy and lithological variation (King, 1981) suggested a division of the London Clay formation into five principal units, named $\mathrm{A}$ to $\mathrm{E}$ in a bottom-up succession. Usually only the lower part of the sequence is preserved, that is, units $\mathrm{C}$ and below. For instance, only units $\mathrm{C}, \mathrm{B}, \mathrm{A} 3$ and $\mathrm{A} 2$ were identified at Heathrow T5.

Gasparre et al. (2007a) made a distinction between structure and nature for London Clay units. The nature of the clay influences intrinsic behaviour, whereas structure separates the mechanical response of different lithological units. Using reconstituted samples, Gasparre \& Coop (2008) determined intrinsic parameters for the LC units at T5. Although the location of the different intrinsic compression line (ICLs) varied for each unit, the slopes of the compression and

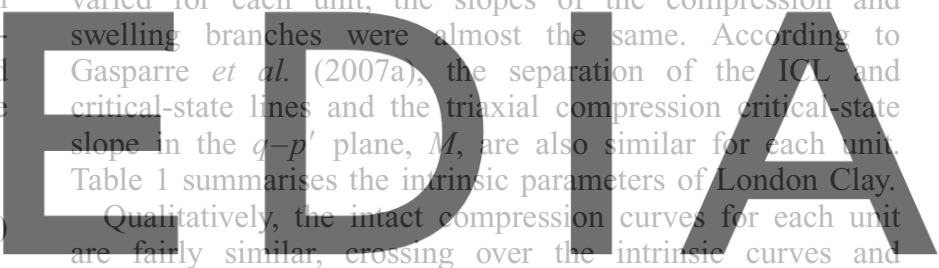

yielding at higher stresses as a result of the structure

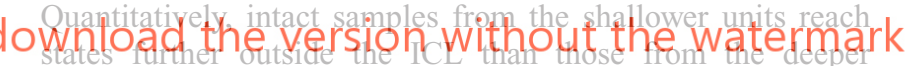
units. This behaviour suggests that the influence of the structure on compression behaviour decreases with depth. Compression curves do not converge towards the ICLs, even at high stresses and large strains. Hight et al. (2007) indicate that this may reflect the presence of clay aggregates, broken down by reconstitution but not by one-dimensional compression.

Gasparre \& Coop (2008) obtained three different quantitative measures of structure from oedometer tests. The first is stress sensitivity, $\left(S_{\sigma}=\sigma_{\mathrm{y}}^{\prime} / \sigma_{\mathrm{e}}^{*}\right)$, defined as the ratio of the yield stress of the natural material to the vertical stress on the ICL at the same void ratio. The second is the yield stress ratio, YSR, defined as YSR $=\sigma_{\mathrm{y}}^{\prime} / \sigma_{0}^{\prime}$, where $\sigma_{\mathrm{y}}^{\prime}$ is the yield stress and $\sigma_{0}^{\prime}$ is the in situ vertical stress. The third is swell sensitivity $\left(S_{\mathrm{s}}=C_{\mathrm{s}}^{*} / C_{\mathrm{s}}\right)$, defined as the ratio of the intrinsic to the intact swelling indices. Table 2 summarises the values obtained for all these structure measures, as well as the estimated yield stress range. As indicated in Table 2, swell sensitivity does vary with the level of stress at which $C_{\mathrm{s}}^{*}$ is measured.

Table 1. Intrinsic parameters of London Clay

\begin{tabular}{l|c|c|c|c|c}
\hline$C_{\mathrm{c}}^{*}$ & $C_{\mathrm{s}}^{*}$ & $\lambda$ & $\kappa$ & $M$ & $\phi_{\mathrm{cs}}:$ degrees \\
\hline $0 \cdot 386$ & $0 \cdot 184$ & $0 \cdot 168$ & $0 \cdot 080$ & $0 \cdot 85$ & 22 \\
\hline
\end{tabular}


Table 2. Summary of yield stress, stress sensitivities and change in swell sensitivity of LC units reported by Gasparre \& Coop (2008)

\begin{tabular}{|c|c|c|c|c|c|c|c|c|c|c|c|c|}
\hline \multirow[t]{2}{*}{ Unit } & \multirow[t]{2}{*}{ Depth: m } & \multirow[t]{2}{*}{$N^{*}$} & \multirow[t]{2}{*}{$e_{0}$} & \multirow[t]{2}{*}{$\begin{array}{l}\text { In situ vertical } \\
\text { stress, } \sigma_{0}^{\prime}: \mathrm{kPa}\end{array}$} & \multicolumn{2}{|c|}{$\begin{array}{c}\text { Yield stress: } \\
\mathrm{kPa}\end{array}$} & \multicolumn{2}{|c|}{$\begin{array}{l}\text { Yield stress } \\
\text { ratio, YSL }\end{array}$} & \multicolumn{2}{|c|}{$\begin{array}{c}\text { Stress } \\
\text { sensitivity, } S_{\sigma}\end{array}$} & \multicolumn{2}{|c|}{$\begin{array}{c}\text { Swell } \\
\text { sensitivity, } S_{\mathrm{s}}\end{array}$} \\
\hline & & & & & $\begin{array}{c}\sigma_{\text {yl }}^{\prime} \\
\text { lower } \\
\text { bound }\end{array}$ & $\begin{array}{c}\sigma_{\text {yu }}^{\prime} \\
\text { upper } \\
\text { bound }\end{array}$ & Min & Max & Min & Max & $\begin{array}{l}\text { At low } \\
\text { stress }\end{array}$ & $\begin{array}{c}\text { At high } \\
\text { stress }\end{array}$ \\
\hline $\mathrm{C}$ & 7 & $2 \cdot 83$ & 0.68 & 110 & 1000 & 2500 & 9 & 23 & $2 \cdot 6$ & $2 \cdot 8$ & 3 & $1 \cdot 5$ \\
\hline $\mathrm{B} 2(\mathrm{c})$ & 10 & 2.95 & $0 \cdot 80$ & 140 & 910 & 2600 & 7 & 19 & $2 \cdot 6$ & $2 \cdot 9$ & $3 \cdot 2$ & $1 \cdot 4$ \\
\hline B2(b) & 17 & & 0.73 & 220 & 2000 & 5200 & 9 & 24 & $2 \cdot 1$ & $2 \cdot 5$ & $2 \cdot 1$ & 1.5 \\
\hline B2(a) & 25 & 3.05 & 0.72 & 260 & 3200 & 6700 & 12 & 26 & $2 \cdot 4$ & $2 \cdot 7$ & $2 \cdot 9$ & $1 \cdot 3$ \\
\hline B2(a) & 28 & & 0.74 & 260 & 2200 & 7075 & 8 & 27 & $2 \cdot 4$ & $2 \cdot 5$ & $2 \cdot 1$ & $1 \cdot 3$ \\
\hline $\mathrm{A} 3(2)$ & 35 & 2.89 & 0.64 & 410 & 3000 & 4100 & 7 & 10 & $2 \cdot 3$ & $2 \cdot 6$ & $1 \cdot 5$ & \\
\hline $\mathrm{A} 3(2)$ & 36 & & 0.71 & 410 & 3200 & 3200 & 8 & 8 & $2 \cdot 1$ & 2 & 1.9 & $1 \cdot 5$ \\
\hline A3(1) & 48 & $2 \cdot 85$ & 0.62 & 530 & 3800 & 9100 & 7 & 17 & $2 \cdot 1$ & $2 \cdot 1$ & $2 \cdot 8$ & $1 \cdot 3$ \\
\hline $\mathrm{A} 2$ & 51 & & 0.57 & 550 & 3000 & 9150 & 5 & 17 & $2 \cdot 3$ & $2 \cdot 4$ & $6 \cdot 7$ & 1.5 \\
\hline
\end{tabular}

* Intrinsic conditions.

London Clay is well known for its apparent variability in undrained strength (Hight et al., 2003). Intact peak effective stress strength is affected by cementing, density and plasticity index. In addition, there is the variability introduced by the presence of fissures or discontinuities. Results of undrained triaxial compression and extension tests for the different lithological units at T5 were presented by Gasparre (2005) and Hight et al. (2007). The stress-strain behaviour of all lithological units was essentially dilatant and strainsoftening, but with strain localisation truncating the dilatant
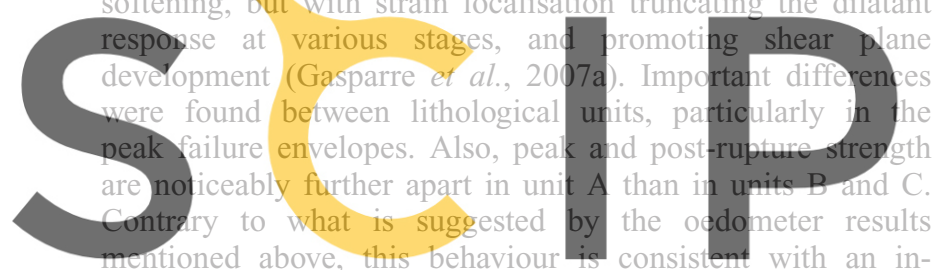

crease of the effect of structure with depth.

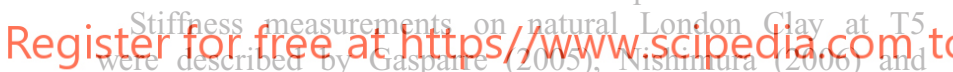
Gasparre et al. (2007b). Modulus decay curves were presented, representing the undrained secant shear modulus, $E_{\mathrm{u}}$, normalised by the value of the mean effective stress prior to the start of undrained shear, $p_{0}^{\prime}$, plotted against axial strain on a $\log$ scale. Two observations are here relevant. First, the curves were similar for all the units; the elastic range was mostly independent of soil structure. Second, the small-strain moduli measured at T5 samples were significantly below most previous database values (Hight et al., 2007).

\section{Model calibration}

The calibration of a complex soil model always benefits from a staged procedure that allows the various sources of information available and their associated uncertainties to be taken into account. Some parameters were less uncertain than others. For instance, the basic parameters of the intrinsic or reference material $(\lambda, \kappa, M)$ were fixed from the outset, using the experimental values quoted in Table 1 . These values were also in good agreement with the values for similar parameters selected by previous modellers (Wongsaroj et al., 2007; Grammatikopoulou et al., 2008).

The basic kinematic-hardening parameters, bubble size $(R)$ and plastic modulus parameter $(B)$ also refer to the reference or intrinsic material, but they have a much less obvious nature. These were assumed as $R=0.016$ and $B=4$, following a previous calibration performed by Grammatikopoulou
(2004) for reconstituted London Clay using a two surface model.

In this work, the calibration effort was focused on the parameters governing the structure $(k, A)$, and on the associated state variables: intrinsic preconsolidation pressure $\left(2 P_{\mathrm{c}}\right)$ and initial structure $\left(r_{0}\right)$. Two sets of experimental results were employed for this purpose: oedometric and triaxial. Since there was considerable uncertainty about the yield point in the oedometer tests, these were used (in combination with information from stress sensitivity and

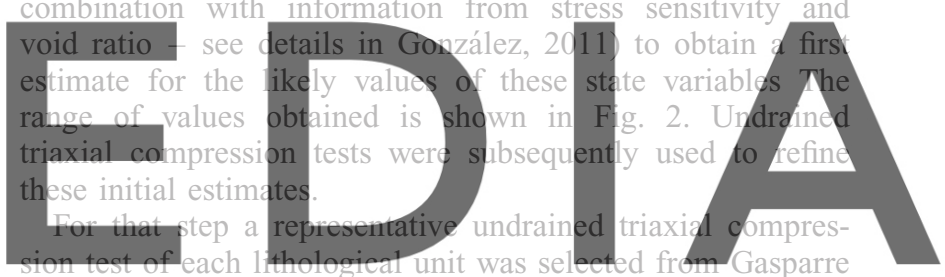

(2005), taking care to avoid the cases where fissure-induced localised shear failure was most evident Stress-strain matched using a trial-and-error procedure. Characteristics of the triaxial tests used for calibration and the resulting parameters for each unit are presented in Table 3. The profiles of initial structure $\left(r_{0}\right)$ and intrinsic preconsolidation pressure $\left(2 P_{\mathrm{c}}\right)$ obtained from the triaxial test calibrations are plotted in Fig. 2. The structure profile thus attained does not present a monotonic trend with depth.

The starting point for estimation of the rate of destructuration $(k)$ was the ratio of low-pressure to high-pressure swell sensitivity $\left(S_{\mathrm{s}}\right)$ from the oedometers. Units A2, B2(a) and $\mathrm{C}$ show a higher degradation rate, whereas units $\mathrm{A} 3$, B2(b) and B2(c) show lower values. The values that, using the undrained triaxial simulations, were finally selected for this parameter (Table 3) maintain that relationship between units. Finally, a constant value of the parameter $A$ equal to 0.75 was selected. This was chosen to fit the dilatant response of the stress-strain curves observed in the undrained triaxial tests.

Example results from the numerical simulations of undrained triaxial tests are presented in Fig. 3 for lithological units B2(a) and A3, which are common to both the T5 and St James's Park sites. Numerical results for the material with and without structure are compared with experimental results given by Gasparre (2005). The difference between the simulations with and without structure is clear. With structure in the model, the strain-softening is somewhat less abrupt than in the experiments, but it does compare favourably with that exhibited in tests where no obvious localisa- 


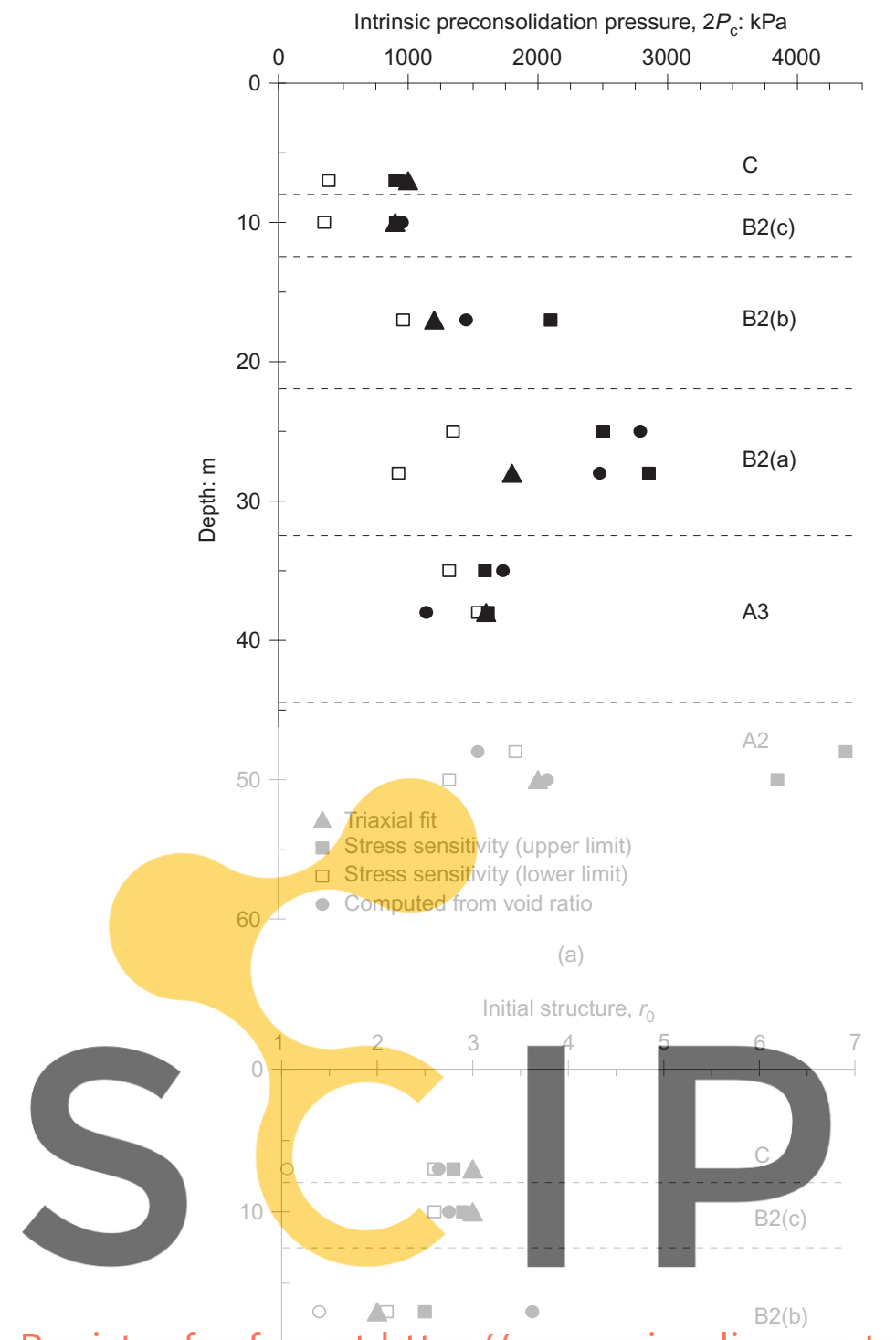

tests of the different lithological units are plotted together with the experimental peak and post-rupture failure envelopes defined by Gasparre (2005). The stress paths obtained using the model reach a different structure-related peak envelope for each unit, and then converge towards a common post-rupture envelope. The simulation for unit B2(c) does not reach the peak triaxial envelope, because the degree of initial structure $\left(r_{0}\right)$ that would be required for that would lie well outside the interval bracketed by the oedometric data in Fig. 2. For lack of specific data in Gasparre (2005), it was assumed that the envelope for A3 was also valid for unit A2.

To choose the parameters controlling small-strain response, consideration was given to model formulation, experimental results and numerical precedent. The model formulation does not relate structure and initial elastic stiffness. Hence the T5 block samples, whose particular value is that they are supposed to keep structure intact to a higher degree than samples from previous studies, do not deserve any special precedence from this point of view.

Moreover, normalised secant modulus decay is not very sensitive to the unit-dependent structure-related parameters (González, 2011), but mostly to parameters that describe the reference material. Of these only the parameter $A_{\mathrm{g}}$ of the elasticity law (equation (2)) was left free at this stage $\left(n_{\mathrm{g}}\right.$ and $m_{\mathrm{g}}$ were chosen using a correlation with plasticity proposed by Viggiani \& Atkinson, 1995). To choose the $A_{\mathrm{g}}$ value, the stiffness at low strains for London Clay is required. Not all sources are in agreement. Fig. 5 shows the experimental data for the A3 unit reported by Gasparre (2005) and Hight et al. (2007) from tests on T5 samples.

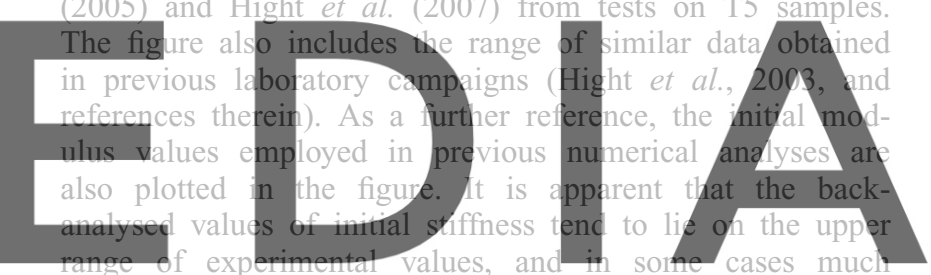

higher stiffness values have been used (Kovacevic et al.,

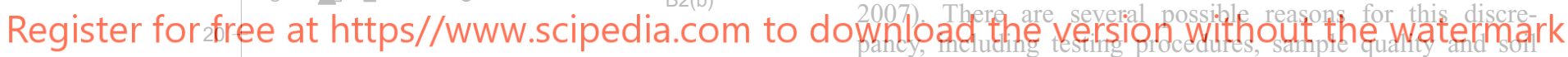

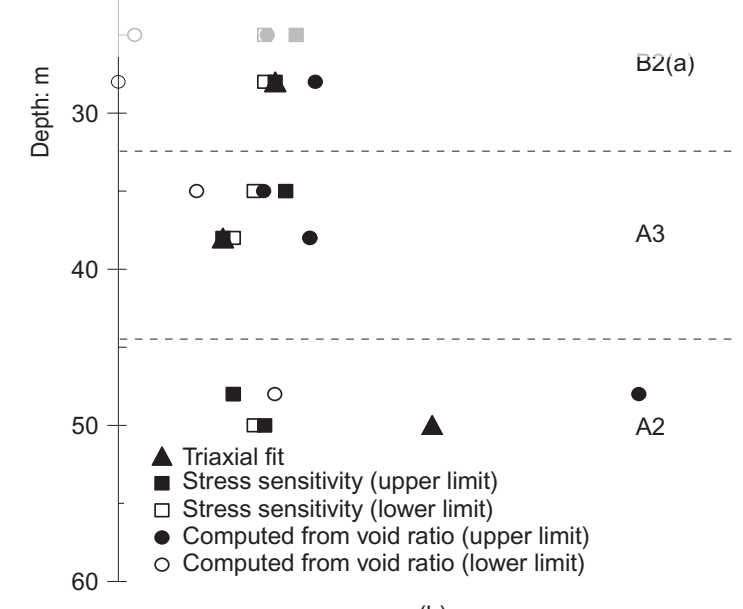

(b)

Fig. 2. Profile of variation of state variables at T5 site: (a) intrinsic preconsolidation pressure; (b) initial structure

tion was noted. Assuming an unstructured material, the behaviour predicted by the model is far more ductile than that observed in the experiments.

In Fig. 4 the compression stress paths for the simulated anisotropy; but until a convincing explanation is produced, a measure of engineering judgement is required.

Against this background, a base case ('high $E_{0}$ ') was established using parameters $A_{\mathrm{g}}=615, \quad n_{\mathrm{g}}=0.87$ and $m_{\mathrm{g}}=0 \cdot 28$; a sensitivity analysis at the element and model scale was performed with a low stiffness case ('low $E_{0}$ ') characterised by $A_{\mathrm{g}}=245$. Normalised modulus decay curves from simulated undrained compression tests for unit A3 are plotted on top of the previous data in Fig. 5, for both stiffness cases with and without structure. They can be seen to span the range of available data. The base case lies on the upper limit of the experimentally supported measures, close to that assumed by previous analysts of the St James's case, but still well below that applied by Kovacevic et al. (2007) at T5. The low elastic stiffness case roughly matches the boundary between the previous lower bound for experimental values and the upper value deduced from the T5 measurements.

The kinematic-hardening structured model (KHSM) has been implemented in the finite-element code PLAXIS V8, which has a facility to implement user-defined (UD) soil models. It uses an explicit stress integration scheme with automatic error control (Sloan et al., 2001; Zhao et al., 2005). The numerical implementation was validated against experimental data and by means of a systematic sensitivity analysis (see González, 2011, for details). The model parameters for London Clay derived from this calibration exercise have been collected in Tables 4 and 5 . 
Table 3. Triaxial tests selected for calibration of model parameters at each lithological unit

\begin{tabular}{|c|c|c|c|c|c|c|c|c|c|}
\hline \multirow[t]{2}{*}{ Unit } & \multirow[t]{2}{*}{ Depth: m } & \multicolumn{3}{|c|}{ Undrained triaxial test } & \multicolumn{5}{|c|}{ Fitted KHSM model parameters } \\
\hline & & Sample name* & $p^{\prime}$ (before shearing): $\mathrm{kPa}$ & $q$ (before shearing): $\mathrm{kPa}$ & $r_{0}$ & $k$ & $A$ & $P_{\mathrm{c}}: \mathrm{kPa}$ & $r P_{\mathrm{c}}: \mathrm{kPa}$ \\
\hline $\mathrm{C}$ & 7 & $7 \mathrm{gUC}$ & 260 & -86 & $3 \cdot 0$ & $1 \cdot 0$ & 0.75 & 500 & 1500 \\
\hline $\mathrm{B} 2(\mathrm{C})$ & $12 \cdot 5$ & $12 \cdot 5 \mathrm{gUC}$ & 260 & -86 & $3 \cdot 0$ & $0 \cdot 5$ & $0 \cdot 75$ & 450 & 1350 \\
\hline B2(B) & $16 \cdot 8$ & $16 \cdot 8 \mathrm{iUC}$ & 200 & 0 & $2 \cdot 0$ & $0 \cdot 5$ & $0 \cdot 75$ & 600 & 1200 \\
\hline B2(A) & $28 \cdot 5$ & $28.5 \mathrm{UC}$ & 400 & 0 & $2 \cdot 5$ & $1 \cdot 0$ & $0 \cdot 75$ & 900 & 2250 \\
\hline $\mathrm{A} 3(2)$ & 38 & $38 \mathrm{UC}$ & 400 & 0 & $2 \cdot 0$ & $0 \cdot 5$ & $0 \cdot 75$ & 800 & 1600 \\
\hline A2 & 51 & $\mathrm{~A} 2^{\dagger}$ & 600 & 0 & $4 \cdot 0$ & $1 \cdot 25$ & $0 \cdot 75$ & 1000 & 4000 \\
\hline
\end{tabular}

* From Table $5 \cdot 4$ of Gasparre (2005).

${ }^{\dagger}$ For unit A2 only oedometer test results were available.
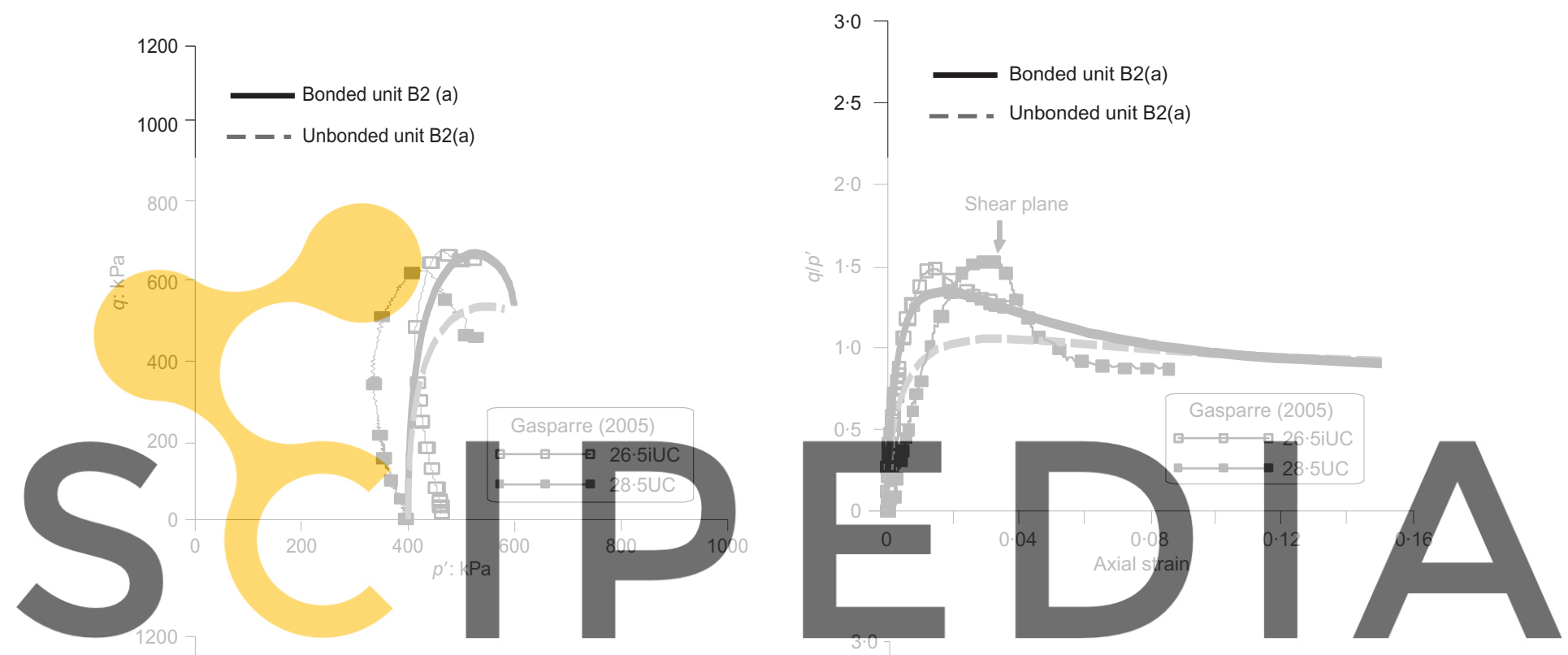

Registerofor free-atobatteps/Awww.scipedia.com to download thended unit As

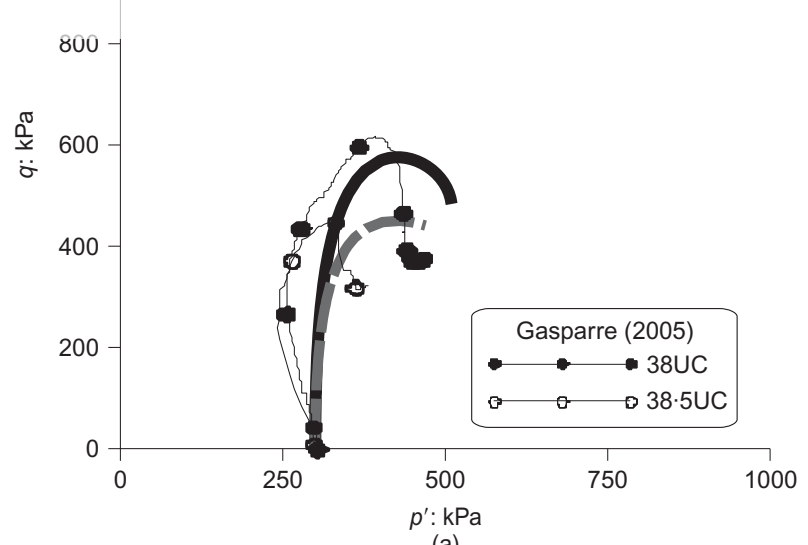

(a)

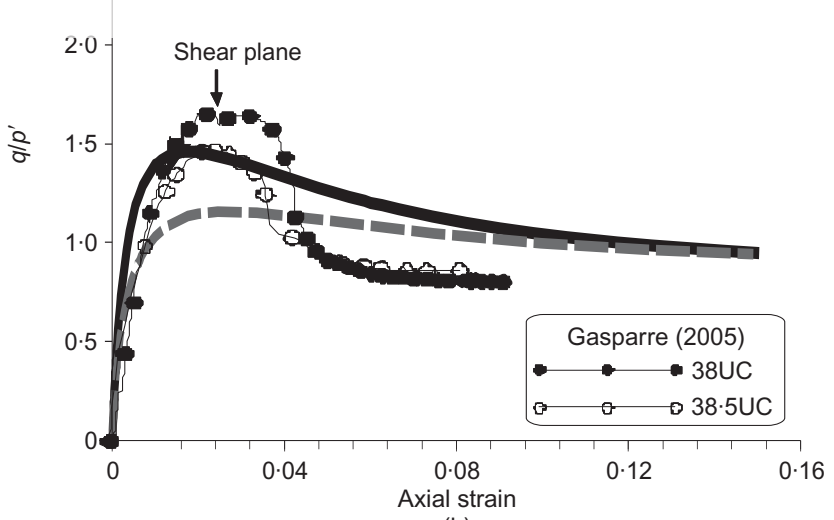

(b)

Fig. 3. Numerical results of undrained triaxial tests for various lithological units at T5: (a) stress path; (b) stress-strain response

NUMERICAL MODEL OF TUNNEL EXCAVATION AT ST JAMES'S PARK

A model was built to represent the excavation of the westbound tunnel of the Jubilee Line Extension (JLE) of the London underground beneath St James's Park. A volume loss of $3 \cdot 3 \%$ was measured in this site, which was unexpectedly high compared with similar cases in London Clay. The profiles at St James's Park and T5 are plotted together in Fig. 6. To ease the comparison they have been matched at the lower boundary of unit B. At the T5 site (Hight et al., 2003) about $4.5 \mathrm{~m}$ of sandy gravel rests directly on a layer of London Clay about $52 \mathrm{~m}$ thick, including lithological units A2, A3, B and C. At St James's Park the soil profile includes, from top to bottom, layers of made ground/allu- 


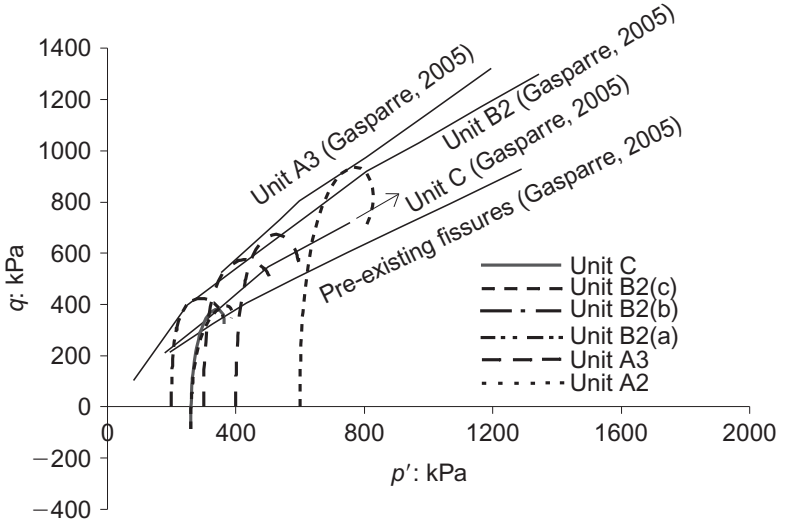

Fig. 4. Stress paths and strength envelopes for various lithological units at $\mathrm{T5}$

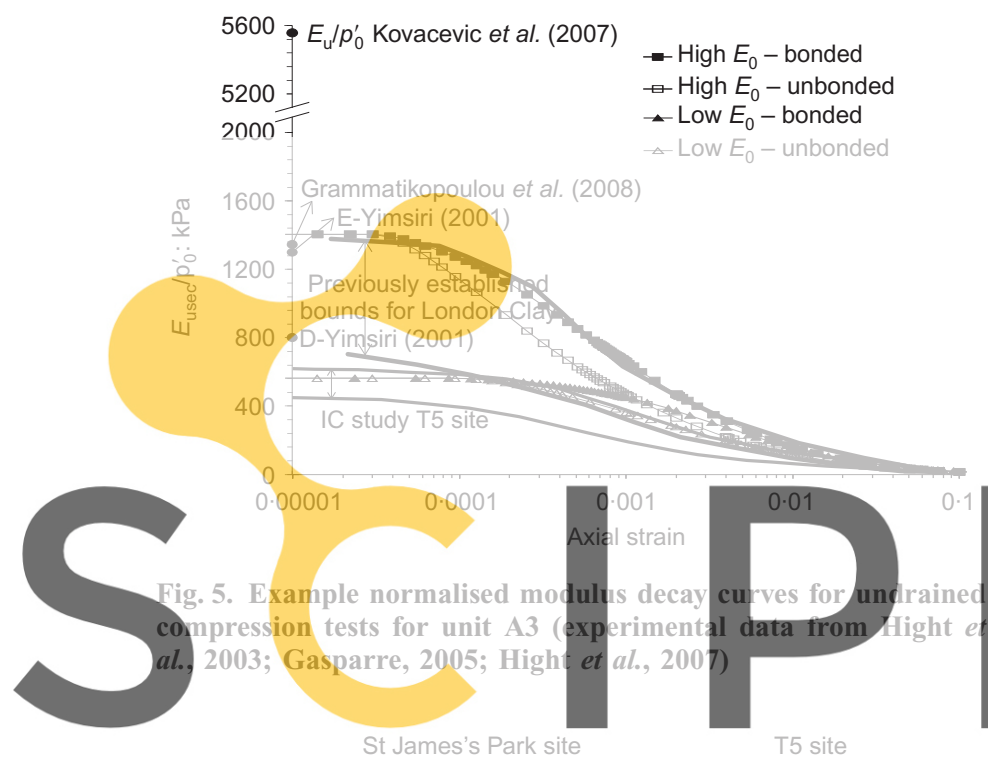

Registek for free at https//WwW.scipedialcom to download the version without the watermark

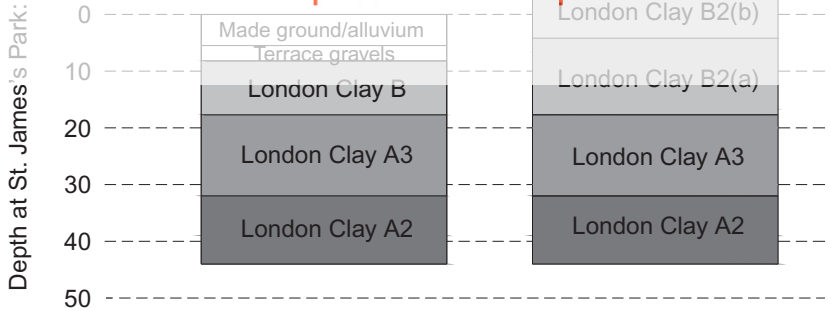

Fig. 6. Profiles of London Clay at St James's Park and T5 sites (matched at $B$ unit lower boundary) vium, Terrace gravel and London Clay, with thickness of at least $32 \mathrm{~m}$ (Standing \& Burland, 2006). Unit C is absent, and unit $\mathrm{B}$ is much thinner than at $\mathrm{T} 5$.

\section{Model geometry and material parameters}

The axis level of the westbound tunnel at St James's Park is about $30.5 \mathrm{~m}$ deep. The tunnel diameter is $4.75 \mathrm{~m}$. The water table was located at the top of the Terrace gravel, and pore pressure was hydrostatic with depth. The finite-element mesh used in the analysis is presented in Fig. 7. Triangular 15 -noded elements were employed. The analyses were conducted under plane-strain conditions.

The London Clay stratum was modelled with the KHSM, using the parameters previously discussed (Tables 3 and 4). Note that only units B2(a), A3 and A2 are present at St James's Park. Terrace gravel and made ground were also modelled with the KHSM, assuming that no structure was present. The kinematic-hardening parameters (Table 5) were fitted to stiffness degradation curves provided in the literature (Addenbrooke et al., 1997; Wongsaroj, 2005). Perfectly undrained behaviour was assumed for London Clay, whereas made ground/alluvium and Terrace gravel were assumed perfectly drained. The lining was modelled as an elastic beam, with the parameters listed in Table 6

\section{Boundary conditions}

The upper boundary is free and the lower boundary fixed. At the sides the horizontal movement is zero. After a parametric analysis (González, 2011), the lateral boundary

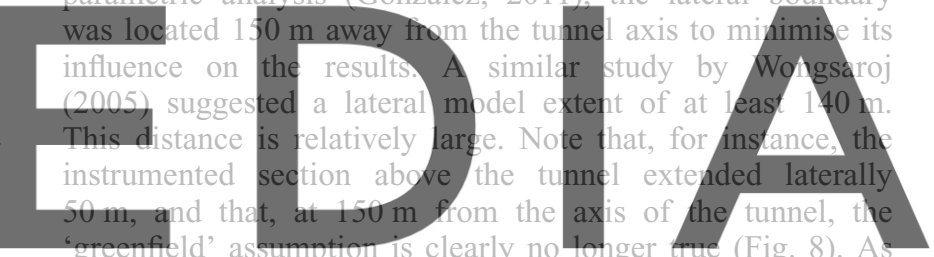

explained below, some care is then required when comparing

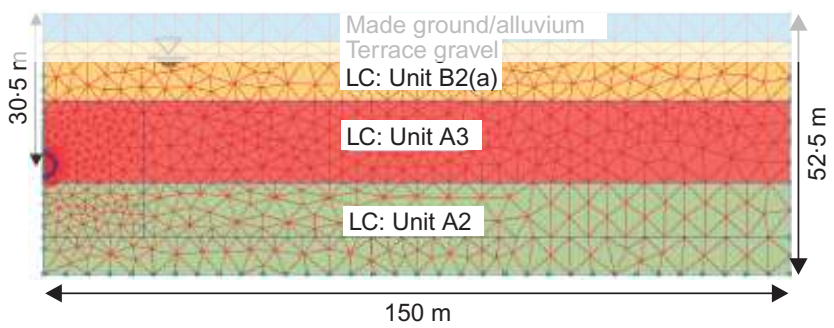

Fig. 7. Geometry and finite-element mesh at St James's Park site

Table 4. London Clay intrinsic parameters for KHSM model

\begin{tabular}{l|c|c|c|c|c|c|c|c}
\hline$\lambda$ & $\kappa$ & $M$ & $\phi_{\text {cs }}:$ degrees & $R$ & $B$ & $A_{\mathrm{g}}$ & $n_{\mathrm{g}}$ & $m_{\mathrm{g}}$ \\
\hline $0 \cdot 168$ & $0 \cdot 080$ & $0 \cdot 85$ & 22 & $0 \cdot 016$ & 4 & $\begin{array}{c}245\left(\text { low } E_{0}\right) \\
615\left(\text { high } E_{0}\right)\end{array}$ & $0 \cdot 87$ & $0 \cdot 28$ \\
\hline
\end{tabular}

Table 5. Material parameters for made ground/alluvium and Terrace gravel

\begin{tabular}{l|c|c|c|c|c|c|c|c|c|c|c|c}
\hline Material & $\gamma_{\text {unsat }}: \mathrm{kN} / \mathrm{m}^{3}$ & $\gamma_{\text {sat }}: \mathrm{kN} / \mathrm{m}^{3}$ & $\lambda$ & $\kappa$ & $e_{0}$ & $M$ & $\phi_{\mathrm{cs}}:$ degrees & $R$ & $B$ & $A_{\mathrm{g}}$ & $n_{\mathrm{g}}$ & $m_{\mathrm{g}}$ \\
\hline $\mathrm{MG} / \mathrm{A}$ & 18 & 20 & $0 \cdot 1$ & $0 \cdot 01$ & $0 \cdot 65$ & $0 \cdot 984$ & 25 & $0 \cdot 0001$ & $0 \cdot 2$ & 165 & $0 \cdot 87$ & $0 \cdot 28$ \\
$\mathrm{TG}$ & 20 & 20 & $0 \cdot 1$ & $0 \cdot 01$ & $0 \cdot 5$ & $1 \cdot 418$ & 35 & $0 \cdot 001$ & 1 & 782 & $0 \cdot 87$ & $0 \cdot 28$ \\
\hline
\end{tabular}


Table 6. Tunnel lining parameters

\begin{tabular}{l|c|c|c|c}
\hline Model & $E A: \mathrm{kN} / \mathrm{m}$ & $E I: \mathrm{kN} \mathrm{m}^{2} / \mathrm{m}$ & $w:(\mathrm{kN} / \mathrm{m}) / \mathrm{m}$ & $v$ \\
\hline Beam elastic & $4.704 \times 10^{6}$ & 11064.00 & 4.03 & 0.15 \\
\hline
\end{tabular}

Unit weight: $24 \mathrm{kN} / \mathrm{m}^{3}$.

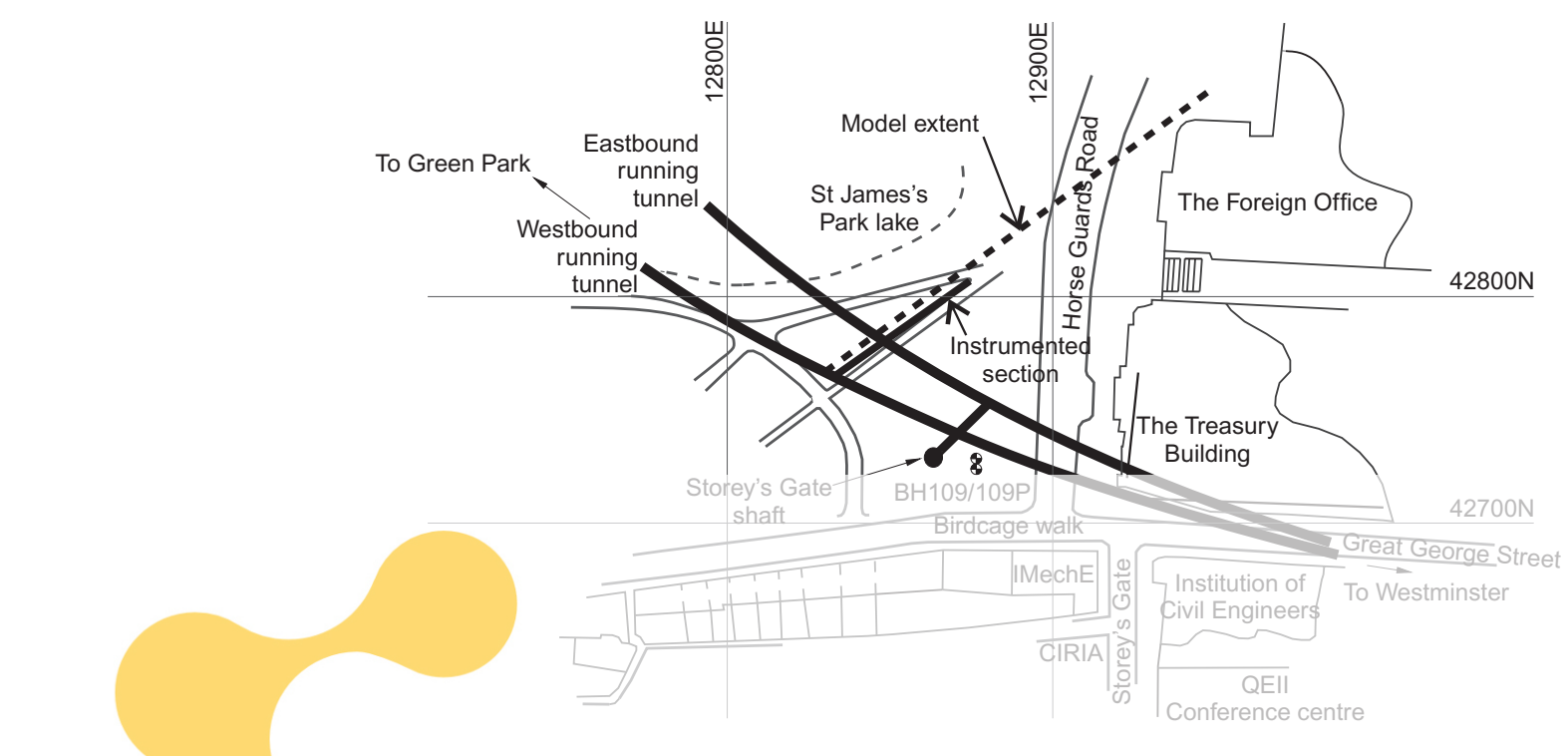

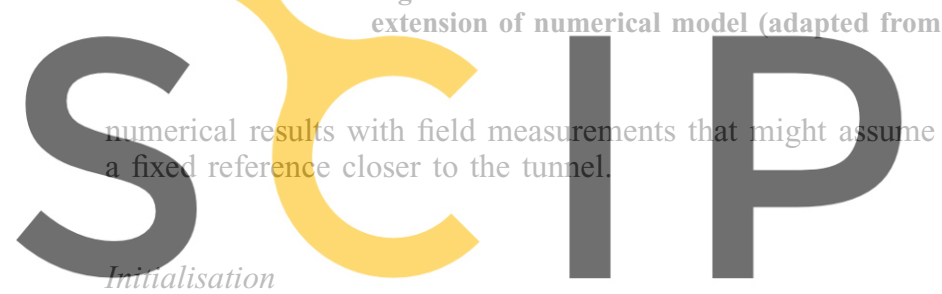

Four field variables require initialisation for materials

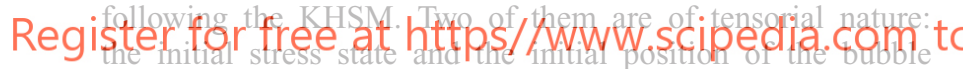
centre $(\alpha)$. Two more are of a scalar nature: the intrinsic preconsolidation pressure $\left(2 P_{\mathrm{c}}\right)$ and the initial structure $\left(r_{0}\right)$.

These field variables are closely linked to the stress history of a site. It is then relevant to note that the T5 and St James's Park sites probably have different geological stress histories (de Freitas \& Mannion, 2007). The T5 site is representative of London Clay towards the west of the London Basin, where a greater thickness of overlying sediments has been removed than in the east (Hight et al., 2003). Based on geological evidence, Chandler (2000) gave an estimate of $200 \mathrm{~m}$ of overburden removed at T5. For St James's Park, a site representative of central London, current estimates of overburden removal (Pantelidou \& Simpson, 2007) point towards an eroded thickness of about $170 \mathrm{~m}$.

Once an erosion thickness is assumed, it is possible to simulate the mechanical loading and unloading history of a site to help initialisation. Any load history subsequent to structure initialisation will result in changes of that variable. Therefore the London Clay deposit was assumed homogeneous (i.e. no differentiation of lithological units), and the development of bonding during the geological history of the clay was neglected. It is difficult to do otherwise, since natural soil structure is a result of poorly understood depositional and post-depositional geological and geochemical processes. This lack of understanding has important modelling repercussions: in the KHSM, structure never increases, but always diminishes with plastic strain. Formally, it is feasible to include in similar models the possibility of an

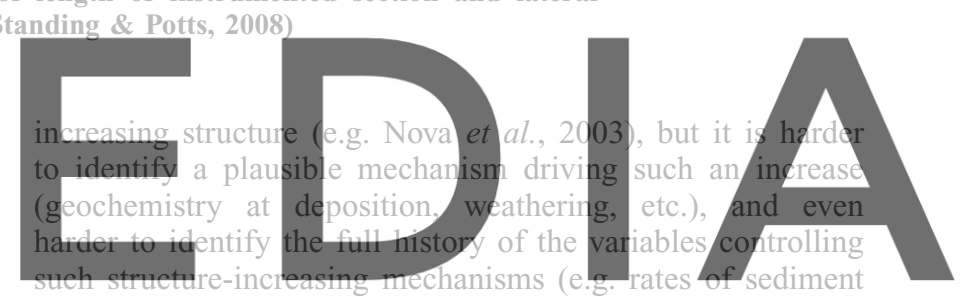

deposition, groundwater flows and composition)

do A stres-history simulation was werented by Grammatiko-nark involved erosion $(180 \mathrm{~m}$ ) of the overlying deposits and the upper part of the London Clay, followed by deposition of the Terrace gravel and alluvium layers. Here, the same exercise has been performed for the T5 site, assuming erosion of $200 \mathrm{~m}$ and deposition of the Terrace gravel. The $K_{0}$ and preconsolidation pressure profiles thus obtained in both the St James's Park and T5 sites are reproduced in Fig. 9. Fig. 9(b) $\left(K_{0}\right)$ also includes a profile by Hight et al. (2003) derived from suction measurements at T5 on thinwall tube samples. Fig. 9(a) (preconsolidation pressure) also includes the profile previously obtained from the calibration of intact London Clay at T5.

At equivalent London Clay depth, the T5 simulation shows higher values of $2 P_{\mathrm{c}}$ and $K_{0}$ than St James's Park, coherent with the larger overburden at T5. Reduced values near the London Clay top are a consequence of reloading by the upper units (Burland et al., 1979). The $K_{0}$ estimated for St James's Park is in close agreement with values from selfboring pressuremeter test measurements (SBP) at Waterloo (Hight et al., 2003), whereas the $K_{0}$ estimated at T5 is in very good agreement with the suction-based estimates, except for samples from the upper $10 \mathrm{~m}$ of the formation, where simulation results and suction measurements diverge. The intrinsic preconsolidation pressure values from the simulation of T5 history are generally below those estimated from the fit of undrained triaxial tests. These divergences may be due partly to the assumption of the material being always unstructured during the stress-history simulations, 


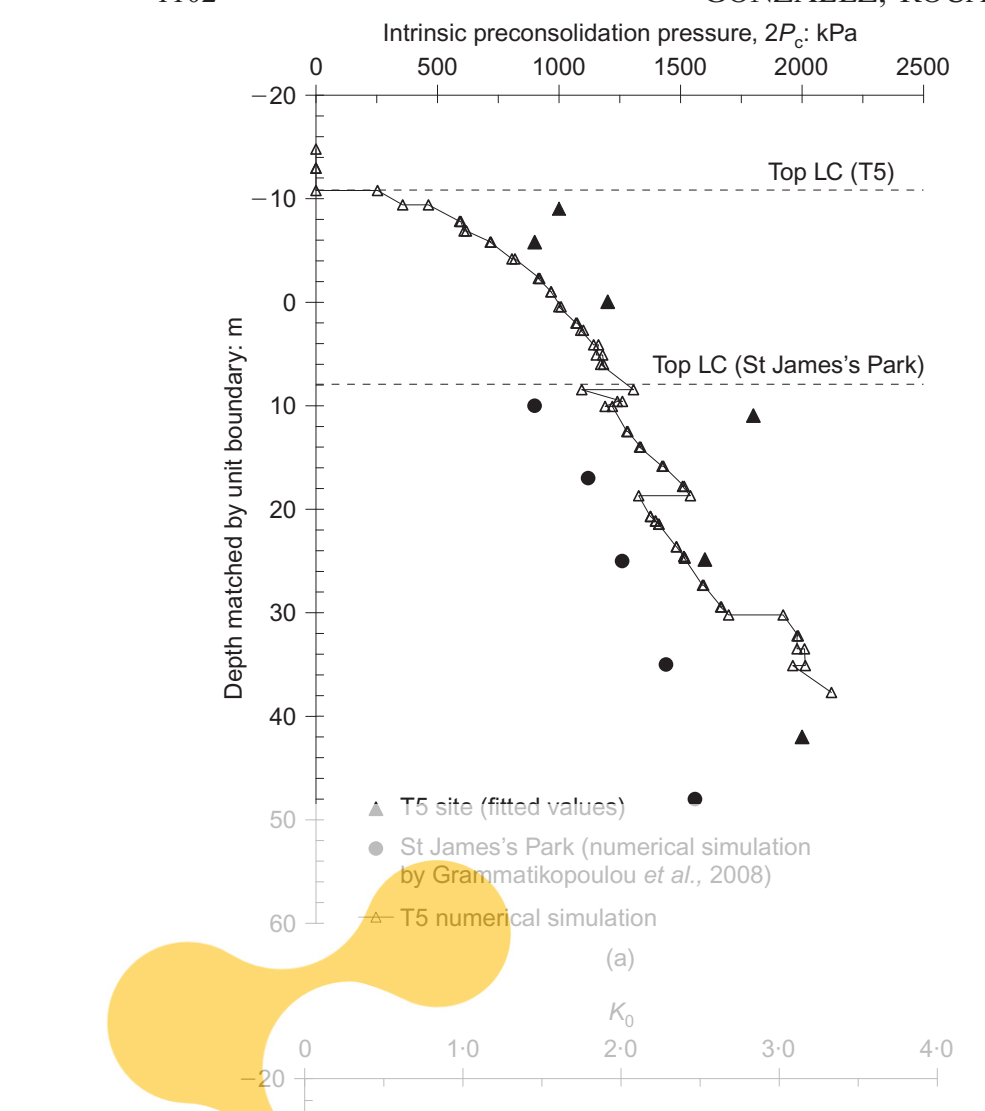

tions without structure) were based on a similar model. London Clay structure at St James's Park was initialised using the T5-calibrated values for units B2(a), A3 and A2. This means that the structure developed during the geological stress history of the clay is considered to be the same for the two sites. This assumption is required by the lack of information about intact properties of London Clay at St James's Park site.

The initial position of the bubble centre, $\alpha$, might be also initialised by using a stress-history simulation. However, experimental work by Clayton \& Heymann (2001) and Gasparre et al. (2007b) appears to indicate that creep erases the stress-history effects associated with the most recent loading. This observation was included in the present analysis by centring the kinematic surface on the current stress state. González (2011) compared this hypothesis and the alternative of keeping the bubble tangent to the initial stress. For both triaxial extension and compression paths only small variations in stiffness decay were observed. The KHSM model behaves differently in this respect from the kinematichardening model of Grammatikopoulou et al. (2008).
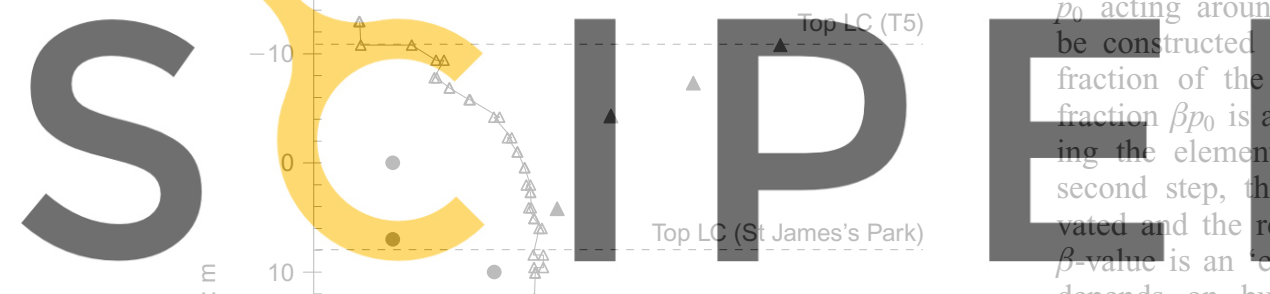

Tunnel modelling

To simulate tunnel excavation in a two-dimensional (2D) finite-element analysis, the effect of the missing third dimension has to be included in some way. Here the stress reduction method or $\beta$ method (Addenbrooke et al., 1997; Möller \& Vermeer, 2008) was employed. The initial stresses

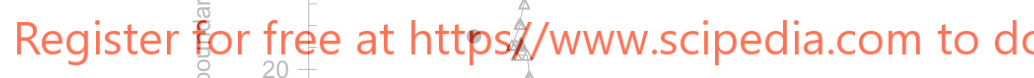
depends on building procedures (e.g. unsupported tunnel

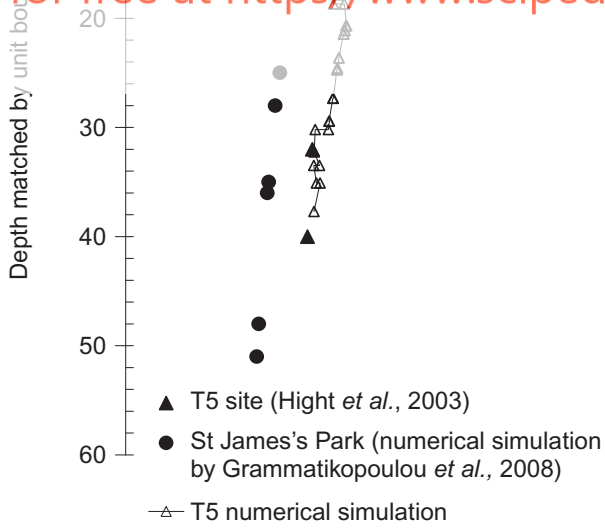

(b)

Fig. 9. Profiles of (a) preconsolidation pressure and (b) $K_{0}$ at $\mathrm{St}$ James's Park and T5 sites (depth matched at B unit lower boundary)

and partly also to measurement uncertainty, at least for the case of the suction-based $K_{0}$.

The profiles of intrinsic preconsolidation pressure and $K_{0}$ derived by Grammatikopoulou et al. (2008) at St James's Park were adopted for the initialisation of the numerical simulation of tunnel excavation. This had the advantage of easing the comparison with their results, which (for simula-

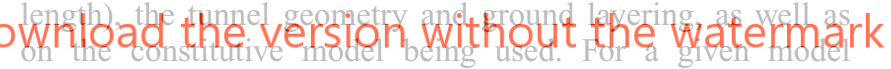
geometry and material description, decreasing $\beta$-values result in increased displacements (tunnel convergence, surface settlements) and decreasing loads on the lining. It is then useful to build generalised ground-response curves such as the one in Fig. 10, relating $\beta$-values to a relevant measure of the ground response. Here that measure was chosen as volume loss, which, assuming undrained behaviour, is equal to the settlement trough area.

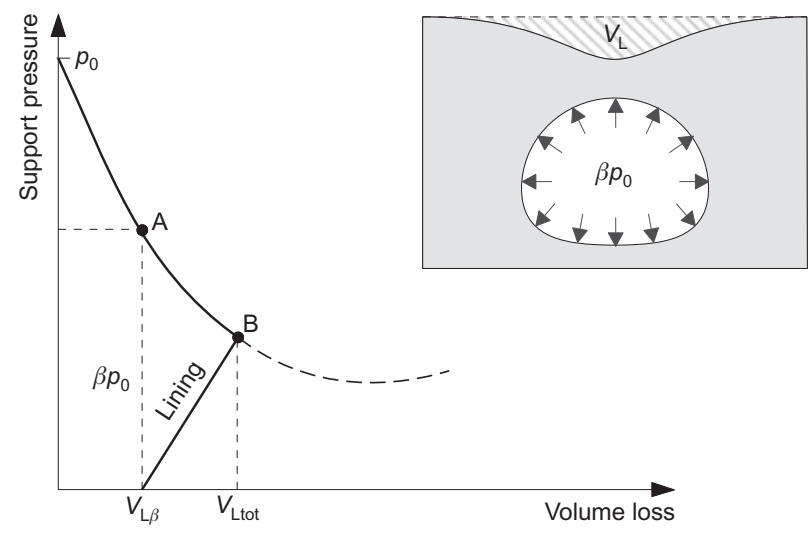

Fig. 10. Display of stress reduction method, adopting groundresponse curve (adapted from Möller, 2006) 


\section{RESULTS}

The measurements at St James's Park are partly described by Standing et al. (1996) and, with emphasis on surface measurements, by Nyren et al. (2001b). Some subsurface measurements from Nyren (1998) were later reproduced by Wongsaroj (2005) and Grammatikopoulou (2004). Standing et al. $(1996,2001)$ describe the instruments and procedures employed to gather the data. In what follows, all the measurements correspond to those taken shortly after the passage of the westbound tunnel, and hence reflect short-term response.

Results from four different analyses are compared with the field measurements. The four analyses combine two hypotheses about the value of small-strain stiffness and two hypotheses about structure in London Clay. With respect to stiffness, the first one ('high $E_{0}$ ') is characterised by a value of the Viggiani \& Atkinson (1995) parameter $A_{\mathrm{g}}=615$, and, for reasons given above, constitutes the base case in the present study. The second one ('low $E_{0}$ ') is characterised by a value $A_{\mathrm{g}}=245$ and, as illustrated in Fig. 5, represents a case close to the values obtained on T5 samples. With respect to structure, the base hypothesis ("bonded") adopted here is that structure is present in London Clay; this is compared with cases ('unbonded') run assuming no structure.

All four analyses were run until the volume loss was close to the $3 \cdot 2 \%$ value measured in the field. The field volume loss was obtained (Nyren et al., 2001) 'by integrating the precision levelling settlement profile and assuming it to be symmetrical'. Field measuring points were located within $52 \mathrm{~m}$ of the tunnel axis: hence no contribution from further afar yas included in the computed

directly checked from the reported

comparable measure of volume

settlement in the numerical mod

from the tunnel axis. The large

boundary (almost $100 \mathrm{~m}$ )

ments in that area (below
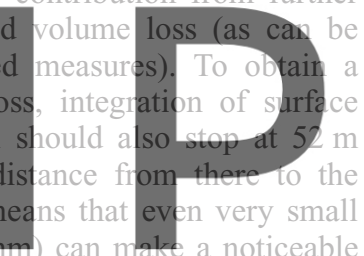

contribution if the volume loss is computed up to the model

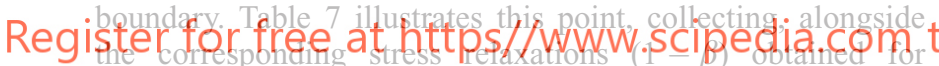

each scenario, the volume loss computed at the target distance $(52 \mathrm{~m})$ and that obtained when integration is extended up to the model boundary $(150 \mathrm{~m})$.

The predicted surface settlement curves are plotted alongside the measured values in Fig. 11. The settlement computed above the crown lies between $71 \%$ and $85 \%$ of the measured value. Surface settlement is more sensitive to the hypothesis about $E_{0}$ than to the consideration of bonding. For both cases of $E_{0}$, however, it seems that the introduction of bonding improves the prediction, and that the improvement is more marked for the case with high $E_{0}$. These effects are also apparent in the normalised settlement curves presented in Fig. 12. Both higher initial stiffness and bonding contribute to a narrower settlement trough, although the effect of initial stiffness is more significant.

Table 7. Volume loss and stress relaxation for the four scenarios analysed

\begin{tabular}{l|c|c|c}
\hline Case & $1-\beta$ & $\begin{array}{c}V_{\mathrm{L}} \text { at } \\
52 \mathrm{~m}: \%\end{array}$ & $\begin{array}{c}V_{\mathrm{L}} \text { at } \\
150 \mathrm{~m}: \%\end{array}$ \\
\hline High $E_{0}-$ unbonded & $0 \cdot 61$ & $3 \cdot 19$ & 3.48 \\
High $E_{0}-$ bonded & $0 \cdot 86$ & $3 \cdot 23$ & 3.55 \\
Low $E_{0}-$ unbonded & 0.58 & $3 \cdot 22$ & 3.68 \\
Low $E_{0}-$ bonded & 0.80 & $3 \cdot 22$ & 3.69 \\
\hline
\end{tabular}

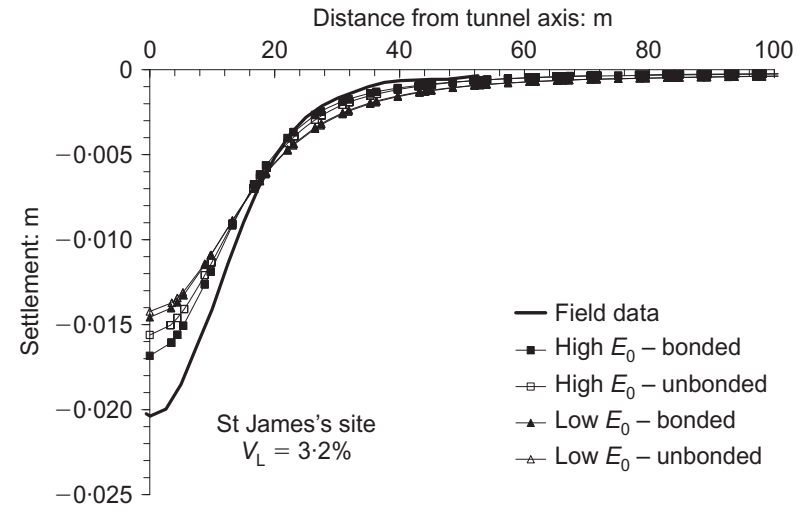

Fig. 11. Measured and computed surface settlement profiles

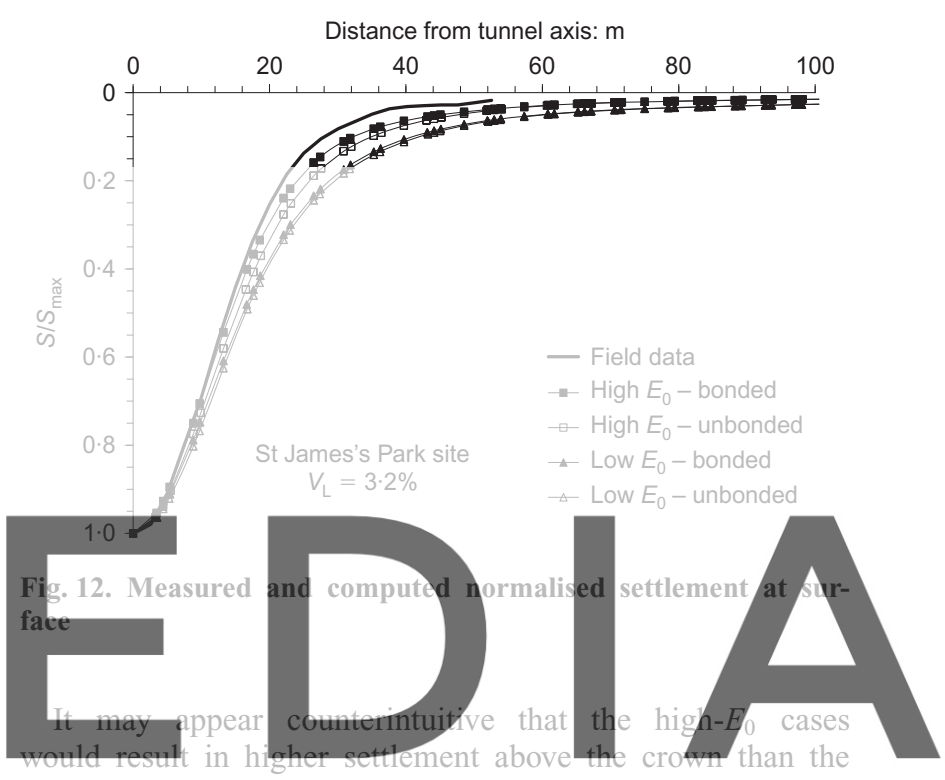

low- $E_{0}$ cases. Actually, that parameter is important only for

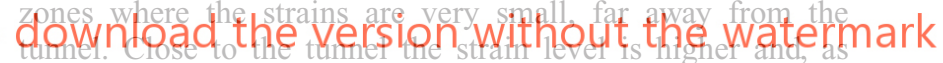
illustrated in Fig. 5, the normalised secant moduli for high and low $E_{0}$ are much closer. The computed values of vertical strain above the crown and close to the tunnel are compared with those derived from rod extensometers in Fig. 13. In the area covered by the measurements, the magnitude of the computed strains in London Clay is very close to or somewhat above that measured. Note that, both in the field and in the simulation, vertical strains above the crown are mostly extensional. This results from the tunnel crown settlement being larger than that at the surface.

Horizontal displacements at the surface were measured using a micrometer stick anchored between each pair of settlement measuring points. To estimate absolute horizontal movements, an assumption of zero displacement at the end line monitoring point is adopted (Standing et al., 2001). For comparison purposes the numerical results are plotted using the same assumption in Fig. 14. The apparent lack of symmetry of the horizontal displacement can be almost fully explained by the offset induced by the non-fixed horizontal datum. Again, the use of the low- $E_{0}$ value suggested by the experiments on T5 block samples would result in a somewhat less accurate prediction; the inclusion of bonding does not appear to enhance the predictions much in this case.

A satisfactory simulation should seek to reproduce well the patterns and magnitudes not only of surface displacements but also of as many subsurface variables as possible. Several electro-level inclinometers were included in the instrumentation at St James's Park (Standing et al., 1996). 


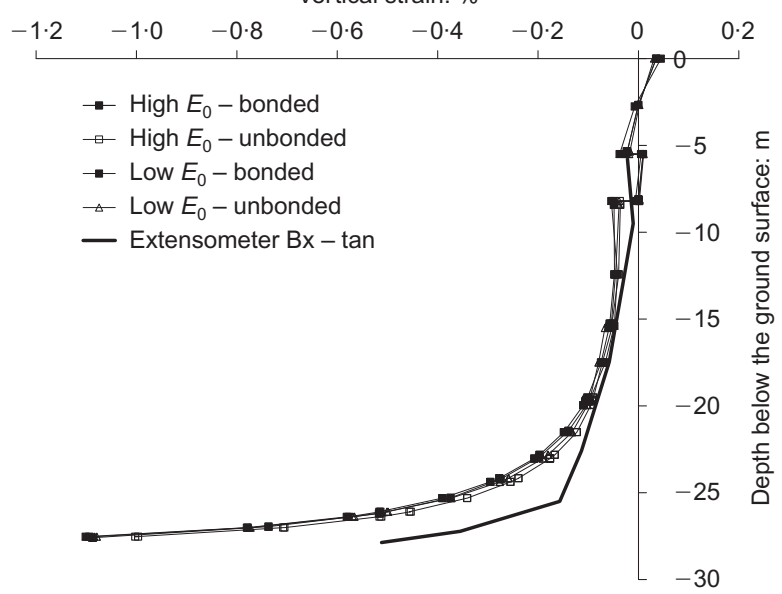

(a)

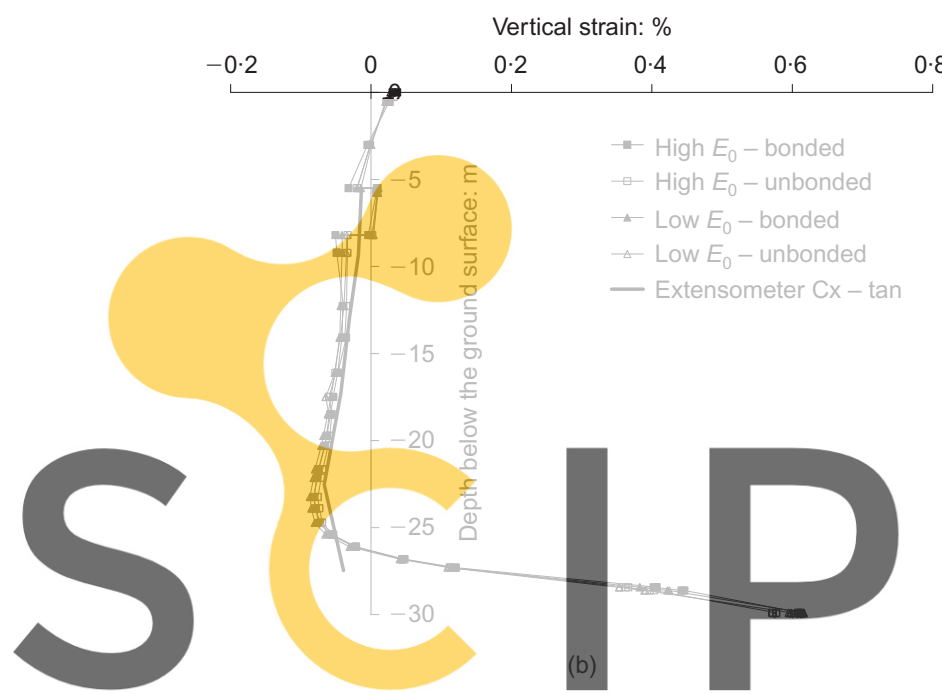

Fig. 13. Computed and measured vertical strains: (a) above Registerofiqre) free at https//WWW.Scipedia.com to do

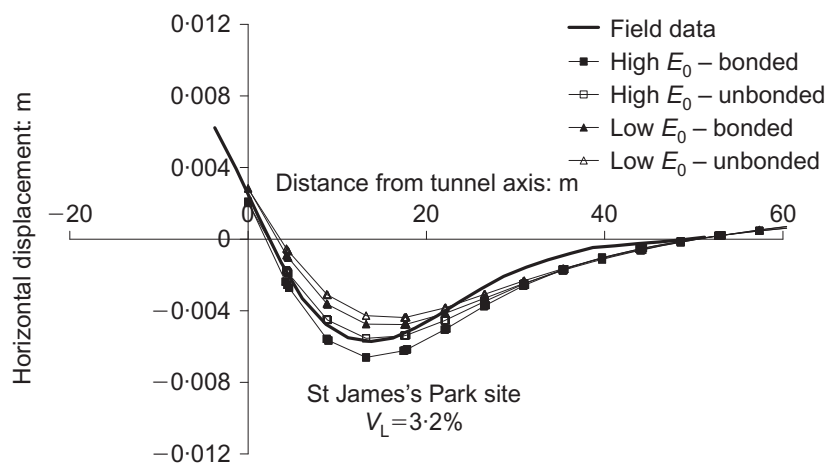

Fig. 14. Measured and computed horizontal displacements at surface. Representation assumes no displacement at $52 \mathrm{~m}$ from axis

Subsurface horizontal displacements are obtained from inclinometer measurements after tying them to some absolute reference, usually the movement at one of the ends of the inclinometer. Here the movement at the surface (Fig. 14) is used for reference. The measurements and model results at six distances from the tunnel axis are plotted in Fig. 15. For clarity, only the simulation results from cases with high $E_{0}$ are represented in the figure. The agreement between measurement and simulation is quite remarkable, the sequence of displacement patterns depending on the distance to the tunnel is well captured, and the quantitative agreement is very good, particularly at the locations closer to the tunnel. The difference between the bonded and unbonded cases is small. As for surface displacements, using a low $E_{0}$ value resulted in a less accurate prediction.

Pore pressures were monitored above the tunnel crown with only two pneumatic piezometers. The computed pore pressure profiles above the tunnel crown and below the tunnel invert are plotted in Fig. 16. A reduction of pore pressures around the tunnel is observed, as a consequence of negative excess pore pressure due to shearing around the tunnel heading. The base case (high $E_{0}$ bonded) is again in good agreement with the measurements. Contrary to most of the previous comparisons, this result is more sensitive to the assumption about bonding than to the assumption about small-strain stiffness. Both unbonded cases result in less excess pore pressure than the two bonded ones.

\section{DISCUSSION \\ Comparison with previous models}

Normalised undrained surface settlements at the St James's Park site found by other authors are plotted together with the extreme results obtained in this study (the base case, high $E_{0}$ bonded and low $E_{0}$ unbonded') in Fig. 17. Both Grammatikopoulou (2004) and Wongsaroj (2005) employed models that could be broadly described as falling within the same kinematic-hardening plasticity category as the unbonded

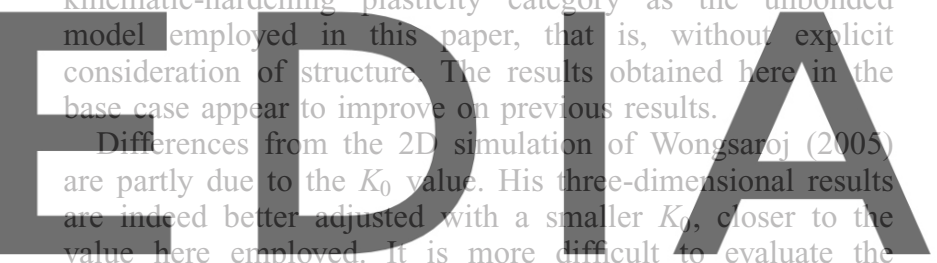

effect of the small-strain stiffness hypothesis, since Wongsar-

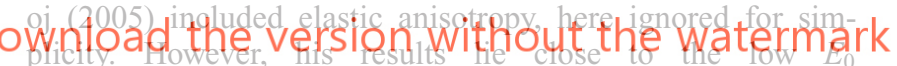
unbonded case, although at a larger total volume loss.

Discrepancy with the results of Grammatikopoulou (2004) is more marked, and cannot be attributed to the $K_{0}$ or intrinsic preconsolidation initial values, because they are the same. The small-strain modulus employed by Grammatikopoulou is also very close to the high- $E_{0}$ hypothesis employed here. It seems likely, then, that the different response of the models is a feature of the different kinematic-hardening formulations employed. A more detailed analysis of where the causes of such differences might lie is beyond the scope of this paper.

\section{Applicability}

It is true that kinematic-hardening models require a relatively large number of parameters, but when the material being modelled has such an extensive history of testing as London Clay, the number of real unknowns is quite small. Of all the remoulded soil parameters that enter the model, the one that has the largest uncertainty is the small-strain stiffness value. The results of the parametric analysis performed here support the application of values close to the upper limit of laboratory-based values. A full reconciliation of the different values obtained in the laboratory with those seemingly relevant for the field is a subject that clearly deserves further study.

As for the structure field and its related parameters, the values obtained here should be taken only as a first ap- 


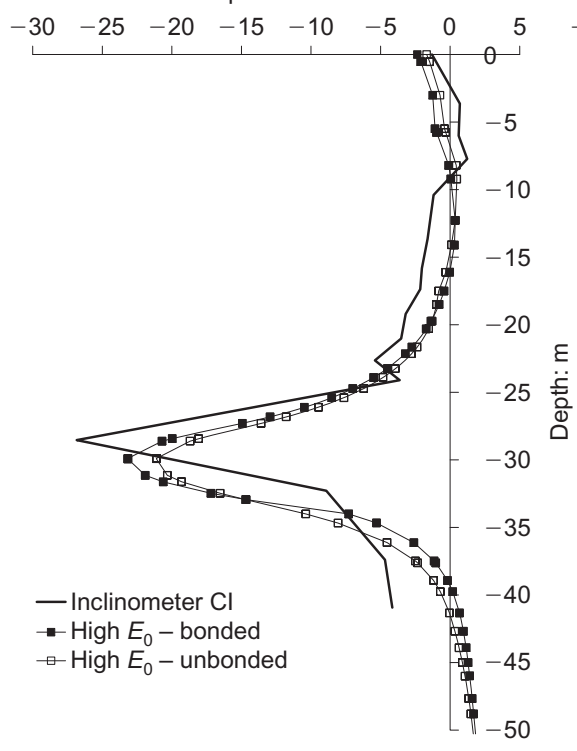

(a)

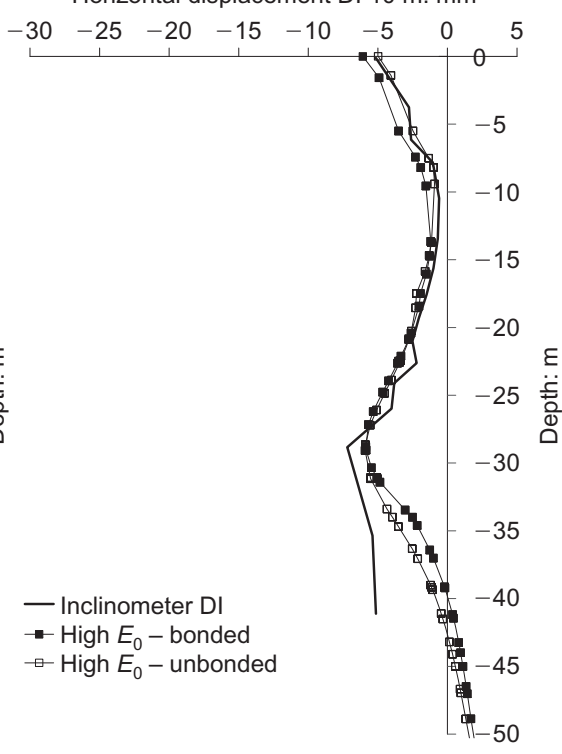

(b)

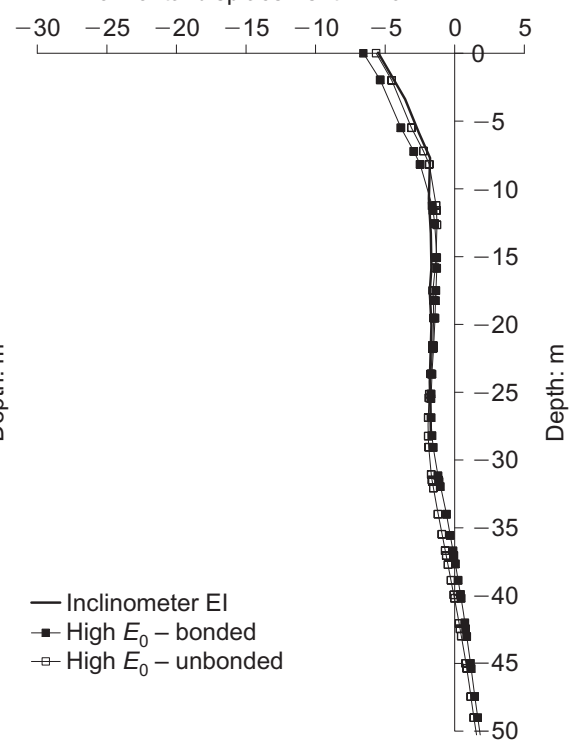

(c)

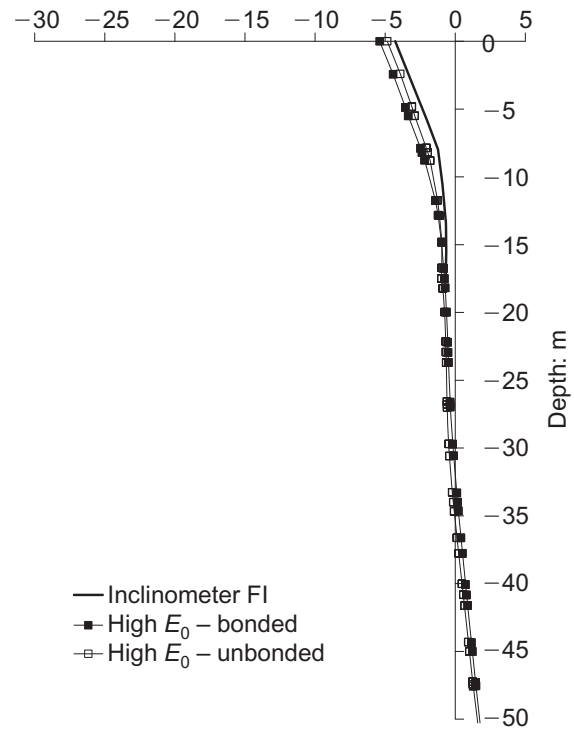

(d)

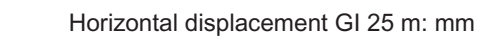

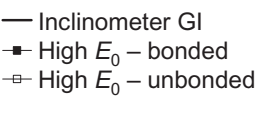

- High $E_{0}$ - bonded
$\square-$ High $E_{0}$ - unbonded

(e)
Horizontal displacement $\mathrm{HI} 31 \mathrm{~m}: \mathrm{mm}$
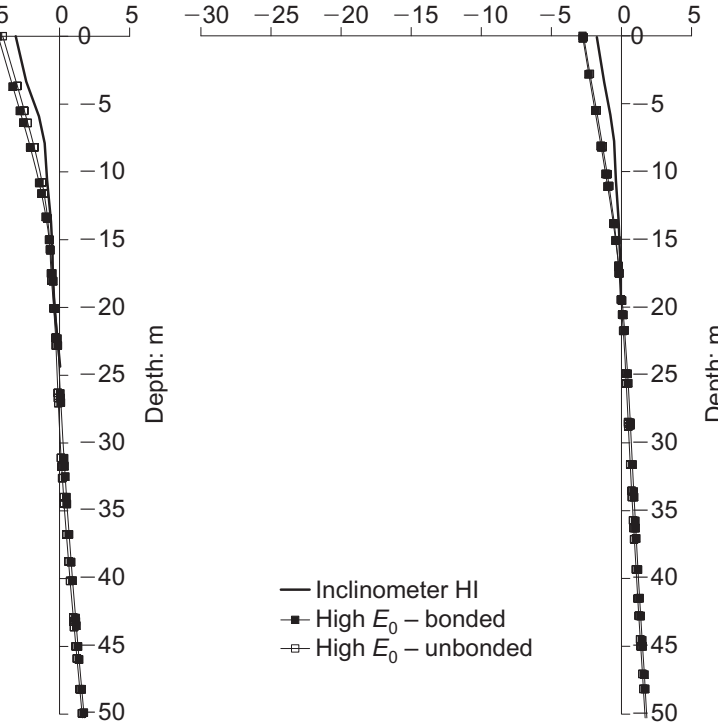

(f)

Fig. 15. Horizontal displacements at depth from inclinometer data and model results (all curves are represented assuming no surface displacement at $52 \mathrm{~m}$ from axis): (a) inclinometer CI $4 \mathrm{~m}$ from tunnel axis; (b) DI, $10 \mathrm{~m}$ from tunnel axis; (c) EI, $16 \mathrm{~m}$ from tunnel axis; (d) FI, $21.5 \mathrm{~m}$ from tunnel axis; (e) GI, $25 \mathrm{~m}$ from tunnel axis; (f) HI, $31 \mathrm{~m}$ from tunnel axis

proach. It is clear, for instance, that the post-yield oedometric behaviour observed on intact samples ('transitional' in the sense of Altuhafi \& Coop, 2011) is not readily replicated by the model. On the other hand, the modelling of the undrained shear response is clearly enhanced by the inclusion of structure in the model. This has clear implications for boundary value problems such as the St James's Park tunnel. Because of its being dominated largely by the pre-gross yield response, a match of field displacements can be replicated without structure, but the relaxed stress levels applied within the excavation are very different. The better adjustment of pore pressure measurements suggests that the stress changes obtained from the bonded cases are better matched to field behaviour. This aspect is important for long-term settlement analysis (Mair \& Taylor, 1997).

\section{GENERALISED GROUND-RESPONSE CURVES AND DESIGN}

Curves relating field volume loss (i.e. computed up to $52 \mathrm{~m}$ from the tunnel) with stress relaxation $(1-\beta)$ for the $\mathrm{St}$ James's Park case are presented in Fig. 18. It is clear that bonded cases require a larger amount of stress relaxation for any given volume loss. Conversely, given any amount of stress relaxation, the volume loss predicted on the unbonded material is significantly larger than that predicted on the bonded material. This is of some consequence from the general viewpoint of design. Since a given value of $2 \mathrm{D}$ stress relaxation represents, in principle, a specific construction procedure, this suggests that modelling without consideration of the bonding level in other London Clay sites will result in conservative settlement predictions and/or conservative lining loads. 


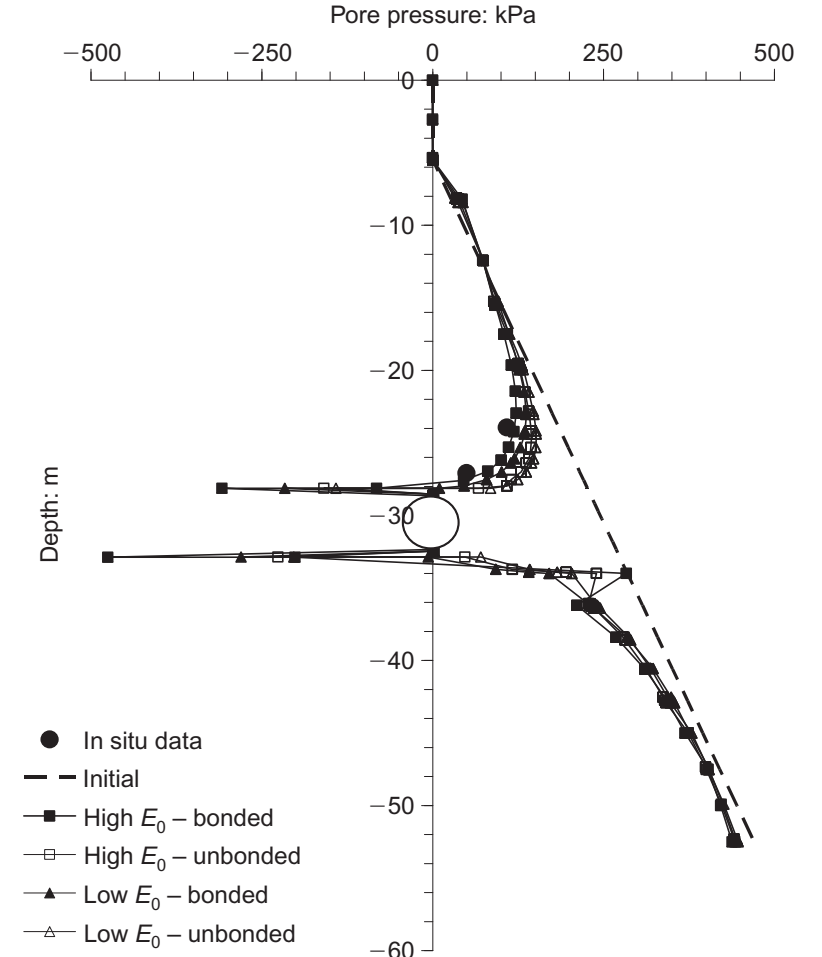

Fig. 16. Computed pore pressure profiles on tunnel axis, and measurements

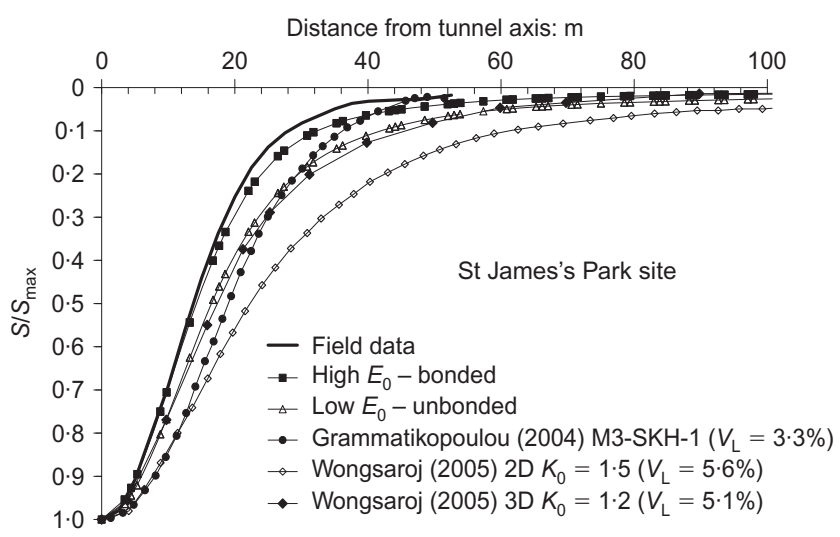

Fig. 17. Computed normalised surface settlement: measured, computed, and reported in the literature

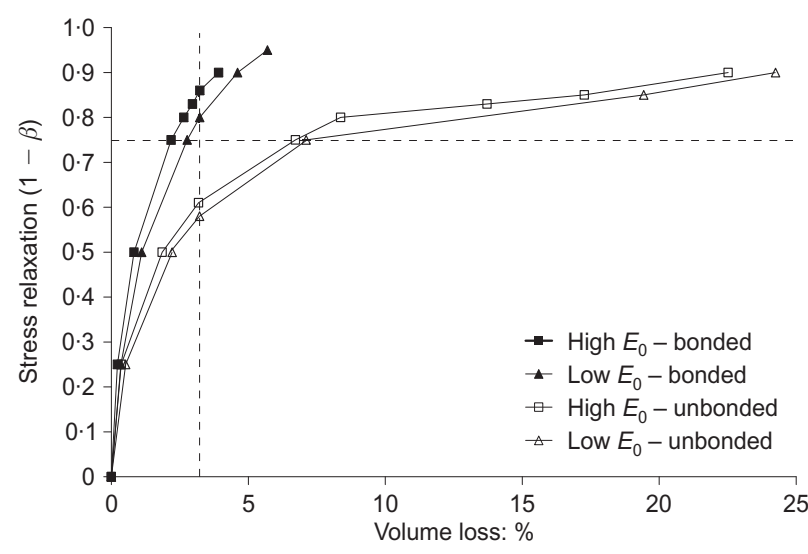

Fig. 18. Relaxation curves for the four cases analysed: vertical dashed line corresponds to volume loss observed at St James's Park; horizontal dashed line to case represented in Fig. 19
It is interesting in this respect to note that, ultimately, the excessive ground loss observed at St James's Park was primarily due to excessive unsupported tunnel excavation length (Standing \& Burland, 2006). In predictive numerical simulations, that would be represented by a high value of stress relaxation $(1-\beta)$. Considering the previous result it might be surmised that a construction procedure involving a large unsupported length could be simulated using a stress relaxation of 0.75 . This simulation approach is illustrated for the St James's Park site in Fig. 19, where it can be also appreciated that the hypothesis about small-strain stiffness has little influence on this result. On the other hand, if a target volume loss is specified at the design stage, the ground-response curves in Fig. 18 suggest that ignoring bonding would result in the use of lower value of stress relaxation and, therefore, in quite conservative estimates of the lining loads.

\section{CONCLUSIONS}

The analyses presented have been performed with a constitutive model that incorporates stiffness degradation and, more significantly, structure. In this way, the distinction between the different lithological units of London Clay can be included in the analysis. The analyses performed of the tunnel excavation at St James's Park have resulted in a very satisfactory reproduction of the magnitude and distributions of short-term surface and subsurface displacements, and a good agreement with the measured pore pressures.

It has also been found that, for a given volume loss, the effects of incorporating structure on the computed displacements are modest. However, the amount of stress relaxation required to achieve a specified volume loss is very different, depending on whether soil structure is considered or not. This difference has direct consequences for some aspects of design, such as expected volume loss, lining loads and excess pore pressures. The possibility of considering a more accurate geological profile in the numerical computations, as well as the good reproduction of field measurements achieved, suggests that there are significant advantages in incorporating structure as a basic state parameter in analyses of tunnelling works involving London Clay. The analysis performed also shows that, despite the large amount of experimental work that has been performed with London Clay, issues still remain, such as the choice of a representative small-strain stiffness value, where model calibration requires a considerable amount of engineering judgement.

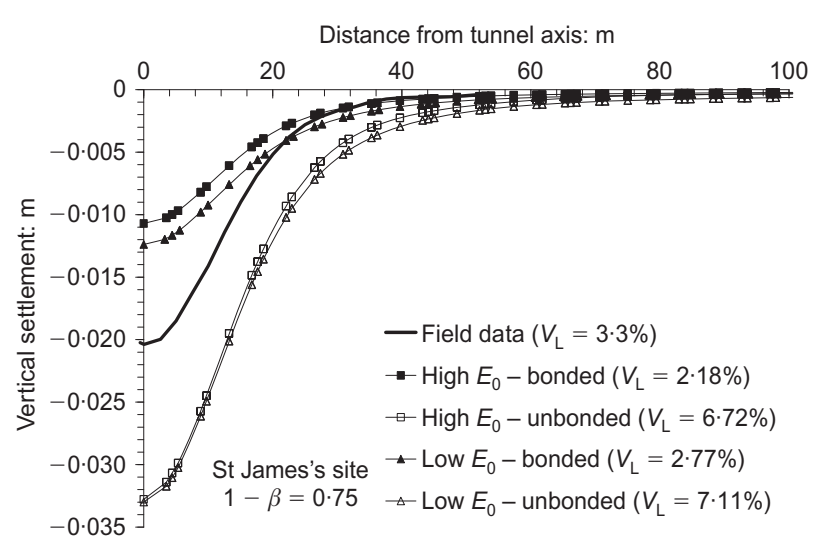

Fig. 19. Surface settlement curves for St James's Park site for design with $75 \%$ stress relaxation 


\section{APPENDIX}

In the KHSM, the reference surface can be written as

$$
f_{\mathrm{r}}=\frac{3}{2 M_{\theta}^{2}} \boldsymbol{s}: \boldsymbol{s}+\left(p^{\prime}-P_{\mathrm{c}}\right)^{2}-\left(P_{\mathrm{c}}\right)^{2}=0
$$

the bubble surface as

$$
f_{\mathrm{b}}=\frac{3}{2 M_{\theta}^{2}}\left(\boldsymbol{s}-\boldsymbol{s}_{\alpha}\right):\left(\boldsymbol{s}-\boldsymbol{s}_{\alpha}\right)+\left(p^{\prime}-p_{\alpha}^{\prime}\right)^{2}-\left(R P_{\mathrm{c}}\right)^{2}=0
$$

and the structure surface as

$$
F=\frac{3}{2 M_{\theta}^{2}}(\boldsymbol{s}):(\boldsymbol{s})+\left(p^{\prime}-r P_{\mathrm{c}}\right)^{2}-\left(r P_{\mathrm{c}}\right)^{2}=0
$$

where $p$ and $\boldsymbol{s}$ are the mean pressure and the deviatoric stress tensor, $\left\{p_{\alpha}^{\prime} \boldsymbol{I}, \boldsymbol{s}_{\alpha}\right\}^{\mathrm{T}}=\overline{\boldsymbol{a}}$ denotes the location of the centre of the bubble, and $\left\{r P_{\mathrm{c}} \boldsymbol{I}\right\}^{T}=\hat{\boldsymbol{a}}$ denotes the centre of the structure surface. The slope of the critical-state line (designated by $M_{\theta}$ ) is expressed as a function of the Lode angle $\theta$, following a proposal by Sheng et al. (2000)

$$
M_{\theta}=M\left[\frac{2 \alpha^{4}}{1+\alpha^{4}+\left(1-\alpha^{4}\right) \sin (3 \theta)}\right]^{1 / 4}
$$

where $M$ is the slope of the CSL under triaxial compression $\left(\theta=-30^{\circ}\right)$.

The scalar variable $r$ is assumed to be a monotonically decreasing function of the plastic strains, and represents the progressive degradation of the material. The incremental form of the destructuration law is written as

$$
\begin{aligned}
\dot{r} & =-\frac{k}{\lambda^{*}-\kappa^{*}}(r-1) \dot{e}_{\mathrm{d}} \\
\dot{e}_{\mathrm{d}} & =\left[(1-A)\left(\dot{\varepsilon}_{\mathrm{v}}^{\mathrm{p}}\right)^{2}+A\left(\dot{\varepsilon}_{\mathrm{q}}^{\mathrm{p}}\right)^{2}\right]^{1 / 2}
\end{aligned}
$$

where $A$ is a non-dimensional scaling parameter, $\dot{\varepsilon}_{\mathrm{v}}^{\mathrm{p}}$ is the plastic volumetric strain rate, $\dot{\varepsilon}_{\mathrm{q}}^{\mathrm{p}}$ is the equivalent plastic shear strain rate, and $\dot{e}_{\mathrm{d}}$ is the destructuration strain rate.

In line with the Cam-clay model, a volumetric hardening rule is adopted in the model, where the change in size of the reference surface, $P_{\mathrm{c}}$, is controlled only by plastic volumetric strain rate $\dot{\varepsilon}_{\mathrm{v}}^{\mathrm{p}}$, given by

$$
\frac{\dot{P}_{\mathrm{c}}}{P_{\mathrm{c}}}=\frac{\dot{\varepsilon}_{\mathrm{v}}^{\mathrm{p}}}{\lambda^{*}-\kappa^{*}}
$$

If a stress increment requires movement of the bubble relative to the structure surface, a simple geometric kinematic-hardening rule is invoked to describe this movement. The translation rule of the centre of the bubble, $\overline{\boldsymbol{a}}$, is

$$
\begin{aligned}
\dot{\overline{\boldsymbol{a}}}= & \overline{\boldsymbol{a}}\left(\frac{\dot{P}_{\mathrm{c}}}{P_{\mathrm{c}}}+\frac{\dot{r}}{r}\right) \\
& +\frac{\dot{\gamma} H-\boldsymbol{n}:\left[\left(\dot{P}_{\mathrm{c}} / P_{\mathrm{c}}\right) \boldsymbol{\sigma}+(\dot{r} / r) \overline{\boldsymbol{a}}\right]}{\boldsymbol{n}:\left(\boldsymbol{\sigma}_{\mathrm{c}}-\boldsymbol{\sigma}\right)}\left(\frac{\boldsymbol{\sigma}-\overline{\boldsymbol{a}}}{R}-\frac{\boldsymbol{\sigma}-\hat{\boldsymbol{a}}}{r}\right)
\end{aligned}
$$

where $R$ is the ratio of the sizes of the elastic bubble and the reference surface, and $\hat{\boldsymbol{a}}$ denotes the location of the centre of the structure surface. It can be shown that the plastic multiplier, $\dot{\gamma}$, can be computed as

$$
\dot{\gamma}=\frac{1}{H}\left(\boldsymbol{n}: \dot{\boldsymbol{\sigma}}^{\prime}\right)=\frac{1}{H_{\mathrm{c}}}\left(\boldsymbol{n}: \dot{\boldsymbol{\sigma}}_{\mathrm{c}}^{\prime}\right)
$$

where the plastic scalar moduli $H$ and $H_{\mathrm{c}}$ are functions of state associated with $\dot{\boldsymbol{\sigma}}^{\prime}$ and $\dot{\boldsymbol{\sigma}}_{\mathrm{c}}^{\prime}$ respectively. $\dot{\boldsymbol{\sigma}}_{\mathrm{c}}^{\prime}$ is the conjugate stress tensor, defined as the point on the structure surface having the same outward normal as the current stress point $\boldsymbol{\sigma}^{\prime}$ on the bubble.

The hardening modulus $H_{\mathrm{c}}$ is derived from the consistency condition on the structure surface for the case where the bubble and the structure surface are in contact. The explicit expression for the plastic modulus $H_{\mathrm{c}}$ takes the form

$$
H_{\mathrm{c}}=\frac{2 r P_{\mathrm{c}}}{\lambda^{*}-\kappa^{*}}\left\{\left(2\left(p-p_{\alpha}\right)+\frac{k(1-r)}{r} \frac{\dot{e}_{\mathrm{d}}}{\dot{\gamma}}\right)\left[\left(p-p_{\alpha}\right)+R P_{\mathrm{c}}\right]\right\}
$$

\section{NOTATION}

A parameter controlling relative proportions of distortional and volumetric destructuration

$A_{\mathrm{g}}, n_{\mathrm{g}}, m_{\mathrm{g}}$ parameters in equation (2) for calculation of elastic shear modulus

$B$ stiffness interpolation parameter

$b$ distance between bubble and structure surface

$b_{\max }^{*}$ maximum value of $b$

$C_{c}^{*} \quad$ intrinsic compression index

$C_{\mathrm{S}}^{c}$ swelling index of intact soil

$C_{\mathrm{s}}^{*}$ intrinsic swelling index

$E_{\mathrm{u}}$ undrained Young's modulus

$E_{0}$ initial modulus

$E A$ normal stiffness of plate elements

EI bending stiffness of plate elements

$e$ void ratio

$e_{0}$ in situ void ratio

$\dot{e}_{\mathrm{d}}$ destructuration strain rate

$F$ structure yield surface

$f_{\mathrm{b}}$ bubble yield surface

$f_{\mathrm{r}}$ reference yield surface

$G$ shear modulus

$H$ plastic modulus

$H_{\mathrm{c}} \quad$ plastic modulus at conjugate stress

ICL intrinsic compression line

$K_{0}$ coefficient of earth pressure at rest

$k$ parameter controlling rate of loss of structure with damage strain

$M$ critical-state stress ratio

$M_{\theta}$ dimensionless scaling function for deviatoric variation of $M$

$N$ intercept of isotropic ICL at $1 \mathrm{kPa}$ on $v-\ln p^{\prime}$ plot

$\boldsymbol{n}$ stress gradient tensor on the bubble

$P_{\mathrm{c}} \quad$ stress variable controlling size of the surfaces

$P_{\mathrm{y}} \quad$ isotropic gross yield pressure

$P_{\mathrm{e}}^{*} \quad$ intrinsic preconsolidation pressure

$p^{\prime}$ mean effective stress

$p_{\mathrm{r}}$ reference pressure in equation (2) for calculation of elastic shear modulus

$p_{\alpha}, \boldsymbol{s}_{\alpha}$ centre of bubble surface

$q$ triaxial deviatoric stress

$R$ ratio of sizes of bubble and reference surface

$R_{0} \quad$ isotropic overconsolidation ratio $\left(=2 P_{\mathrm{c}} / p^{\prime}\right)$

$r$ parameter describing ratio of sizes of structure and reference surfaces

$r_{0}$ initial value of $r$

$S_{\mathrm{s}} \quad$ swell sensitivity

$S_{\sigma} \quad$ stress sensitivity

$\boldsymbol{s}$ deviatoric stress tensor

$V_{\mathrm{L}}$ volume loss

$w$ weight (force per unit area) of plate elements

YSR yield stress ratio

$\alpha$ parameter linking $M_{\theta}$ and $M$

$\overline{\boldsymbol{a}}$ location of centre of bubble

$\hat{\boldsymbol{a}}$ location of centre of reference surface

$\beta$ factor of stress reduction method

$\boldsymbol{\beta}$ tensor connecting current stress state on the bubble surface to the conjugate point on the structure surface

$\dot{\gamma}$ plastic multiplier

$\gamma_{\text {sat }}$ saturated unit weight of the soil (below the phreatic level)

$\gamma_{\text {unsat }}$ unsaturated unit weight of the soil (above the phreatic level)

$\varepsilon_{\mathrm{q}}^{\mathrm{p}} \quad$ plastic deviatoric strain

$\varepsilon_{\mathrm{v}}^{\mathrm{p}} \quad$ plastic volumetric strain

$\theta$ Lode angle

$\kappa$ slope of isotropic swelling line (in $e-\ln p^{\prime}$ space)

$\kappa^{*}$ slope of isotropic swelling line (in $\ln e-\ln p^{\prime}$ space)

$\lambda$ slope of isotropic compression line (in $e-\ln p^{\prime}$ space) 
$\lambda^{*}$ slope of isotropic compression line (in $\ln e-\ln p^{\prime}$ space)

$v$ Poisson's ratio

$\boldsymbol{\sigma}^{\prime}$ effective stress tensor

$\boldsymbol{\sigma}_{\mathrm{c}}^{\prime}$ conjugate effective stress tensor

$\sigma_{\mathrm{e}}^{*} \quad$ equivalent $\sigma_{v}^{\prime}$ on ICL at current void ratio

$\sigma_{\mathrm{h}}, \sigma_{\mathrm{v}}$ horizontal and vertical total stresses

$\sigma_{\mathrm{h}}^{\prime}, \sigma_{\mathrm{v}}^{\prime}$ horizontal and vertical effective stresses

$\sigma_{\mathrm{y}}^{\prime}$ gross yield stress during compression

$\sigma_{0}^{\prime}$ in situ vertical effective stress

$\varphi_{\mathrm{cs}}^{\prime}$ angle of shear strength at critical state

\section{REFERENCES}

Addenbrooke, T. I., Potts, D. M. \& Puzrin, A. M. (1997). The influence of pre-failure soil stiffness on the numerical analysis of tunnel construction. Géotechnique 47, No. 3, 693-712, http:// dx.doi.org/10.1680/geot.1997.47.3.693.

Altuhafi, F. N. \& Coop, M. R. (2011). Changes to particle characteristics associated with the compression of sands. Géotechnique 61, No. 6, 459-471, http://dx.doi.org/10.1680/geot.9.P.114.

Baudet, B. \& Stallebrass, S. (2004). A constitutive model for structured clays. Géotechnique 54, No. 4, 269-278, http://dx. doi.org/10.1680/geot.2004.54.4.269.

Burland, J. B. (1990). On the compressibility and shear strength of natural soils. Géotechnique 40, No. 3, 329-378, http://dx.doi. org/10.1680/geot.1990.40.3.329.

Burland, J. B., Simpson, B. \& St John, H. D. (1979). Movements around excavations in London Clay. Proc. 7th Eur. Conf. Soil Mech. Found. Engng, Brighton 1, 13-20.

Clayton, C. \& Heymann, G. (2001). Stiffness of geomaterials at very small strains. Géotechnique 51, No. 3, 245-255, http://dx. doi.org/10.1680/geot.2001.51.3.245.

Chandler, R. J. (2000). Clay sediments in depositional basins: the geotechnical cycle. Q. J. Engng Geol. Hydrogeol. 33, No. 1, 7-39.

Cotecchia, F. \& Chandler, R. J. (1997). The influence of structure on the pre-failure behaviour of a natural clay. Géotechnique 47, No. 3, 523-544, http://dx.doi.org/10.1680/geot.1997.47.3.523.

de Freitas, M. H. \& Mannion, W. G. (2007). A biostratigraphy for the London Clay in London. Géotechnique 57, No. 1, 91-99, http://dx.doi.org/10.1680/geot.2007.57.1.91.

Franzius, J. N., Potts, D. M. \& Burland, J. B. (2005). The influence of soil anisotropy and $K_{0}$ on ground surface movements resulting from tunnel excavation. Géotechnique 55, No. 3, 189-199, http://dx.doi.org/10.1680/geot.2005.55.3.189.

Gasparre, A. (2005). Advanced laboratory characterisation of London Clay. PhD thesis, Imperial College, London, UK.

Gasparre, A. \& Coop, M. R. (2008). Quantification of the effects of structure on the compression of a stiff clay. Can. Geotech. J. 45, No. 9, 1324-1334.

Gasparre, A., Nishimura, S., Coop, M. R. \& Jardine, R. J. (2007a). The influence of structure on the behaviour of London Clay. Géotechnique 57, No. 1, 19-31, http://dx.doi.org/10.1680/geot. 2007.57.1.19.

Gasparre, A., Nishimura, S., Anh-Minh, N., Coop, M. R. \& Jardine, R. J. (2007b). The small strain behaviour of natural London Clay. Géotechnique 57, No. 1, 33-47, http://dx.doi.org/10.1680/ geot.2007.57.1.33.

González, N. A. (2011). Development of a family of constitutive models for geotechnical applications. $\mathrm{PhD}$ thesis, Universitat Politécnica de Catalunya, Barcelona, Spain.

González, N., Arroyo, M. \& Gens, A. (2009). Identification of bonded clay parameters in SBPM tests: a numerical study. Soils Found. 49, No. 3, 329-340.

Grammatikopoulou, A. (2004). Development, implementation and application of kinematic hardening models for overconsolidated clays. $\mathrm{PhD}$ thesis, Imperial College, London, UK.

Grammatikopoulou, A., Zdravkovic, L. \& Potts, D. M. (2006). General formulation of two kinematic hardening constitutive models with a smooth elastoplastic transition. Int. J. Geomech. 6, No. 5, 291-302.

Grammatikopoulou, A., Zdravkovic, L. \& Potts, D. M. (2008). The influence of previous stress history and stress path direction on the surface settlement trough induced by tunnelling. Géotechnique 58, No. 4, 269-281, http://dx.doi.org/10.1680/geot.2008.58.4.269.
Hight, D. W., McMillan, F., Powell, J. J. M., Jardine, R. J. \& Allenou, C. P. (2003). Some characteristics of London Clay. In Characterisation and engineering properties of natural soils (eds T. S. Tan, K. K. Phoon, D. W. Hight and S. Leroueil), Vol. 2, pp. 851-907. Lisse, the Netherlands: Balkema.

Hight, D. W., Gasparre, A., Nishimura, S., Minh, N. A., Coop, M. R. \& Jardine, R. J. (2007). Characteristics of the London Clay from the Terminal 5 site at Heathrow airport. Géotechnique 57, No. 1, 3-18, http://dx.doi.org/10.1680/geot.2007.57.1.3.

Karstunen, M., Krenn, H., Wheeler, S. J., Koskinen, M. \& Zentar, R. (2005). The effect of anisotropy and destructuration on the behaviour of Murro test embankment. Int. J. Geomech. ASCE 5, No. 2, 87-97.

Kavvaddas, M. \& Amorosi, A. (2000). A constitutive model for structured soils. Géotechnique 50, No. 3, 263-273, http://dx. doi.org/10.1680/geot.2000.50.3.263.

King, C. (1981). The stratigraphy of the London Basin and associated deposits, Tertiary Research Special Paper 6. Rotterdam, the Netherlands: Backhuys.

Kovacevic, N., Hight, D. W. \& Potts, D. M. (2007). Predicting the stand-up time of temporary London Clay slopes at Terminal 5 , Heathrow airport. Géotechnique 57, No. 1, 63-74, http://dx.doi. org/10.1680/geot.2007.57.1.63.

Mair, R. J. \& Taylor, R. N. (1997). Theme Lecture: Bored tunnelling in the urban environment. Proc. 14th Int. Conf. Soil Mech. Found. Engng, Hamburg 4, 2353-2385.

Möller, S. C. (2006). Tunnel induced settlements and structural forces in linings. $\mathrm{PhD}$ thesis, Universität Stuttgart, Germany.

Möller, S. C. \& Vermeer, P. A. (2008). On numerical simulation of tunnel installation. Tunnel. Underground Space Technol. 23, No. 4, 461-475.

Nishimura, S. (2006). Laboratory study on anisotropy of natural London Clay. PhD thesis, Imperial College, London, UK.

Nova, R., Castellanza, R. \& Tamagnini, C. (2003). A constitutive model for bonded geomaterials subject to mechanical and/or chemical degradation. Int. J. Numer. Anal. Meth. Geomech. 27, No. 9, 705-732.

Nyren, R. (1998). Field measurement above twin tunnel in London Clay. PhD thesis, Imperial College, University of London, UK.

Nyren, R. J., Standing, J. R. \& Burland, J. B. (2001). Surface displacements at St James's Park greenfield reference site above twin tunnels through the London Clay. In Building response to tunnelling: Case studies from construction of Jubilee Line Extension, London (eds J. B. Burland, J. R. Standing and F. M. Jardine), Vol. 2, pp. 387-400. London, UK: CIRIA/Thomas Telford.

Panayides, S. \& Rouainia, M. (2010). Undrained ultimate capacity of suction anchors using an advanced constitutive model. In Numerical methods in geotechnical engineering (eds T. Benz and S. Nordal), pp. 993-938. London, UK: Taylor \& Francis Group.

Pantelidou, H. \& Simpson, B. (2007). Geotechnical variation of London Clay across central London. Géotechnique 57, No. 1, 101-112, http://dx.doi.org/10.1680/geot.2007.57.1.101.

Rouainia, M. \& Wood, D. (2000). A kinematic hardening constitutive model for natural clays with loss of structure. Géotechnique 50, No. 2, 153-164, http://dx.doi.org/10.1680/geot.2000.50.2. 153.

Sheng, D., Sloan, S. W. \& Yu, H. S. (2000). Aspects of finite element implementation of critical state models. Comput. Mech. 26, No. 2, 185-196.

Sloan, S. W., Abbo, A. J. \& Sheng, D. (2001). Refined explicit integration of elasto-plastic models with automatic error control. Engng Comput. 18, No. 1, 121-154.

Smith, P. R., Jardine, R. J. \& Hight, D. W. (1992). The yielding of Bothkennar Clay. Géotechnique 42, No. 2, 257-274, http:// dx.doi.org/10.1680/geot.1992.42.2.257.

Standing, J. R. \& Burland, J. B. (2006). Unexpected tunnelling volume losses in the Westminster area, London. Géotechnique 56, No. 1, 11-26, http://dx.doi.org/10.1680/geot.2006.56.1.11.

Standing, J. R. \& Potts, D. M. (2008). Contributions to Géotechnique 1948-2008: Tunnelling. Géotechnique 58, No. 5, 391-398, http://dx.doi.org/10.1680/geot.2008.58.5.391.

Standing, J. R., Nyren, R. J., Burland, J. B. \& Longworth, T. I. (1996). The measurement of ground movements due to tunnelling at two control sites along the Jubilee Line Extension. In 
Geotechnical aspects of underground construction in soft ground (eds R. J. Mair and R. N. Taylor), pp. 751-756. Rotterdam, the Netherlands: Balkema.

Standing, J. R., Withers, A. D. \& Nyren, R. J. (2001). Measuring techniques and their accuracy. In Building response to tunnelling (eds J. B. Burland, J. R. Standing and F. M. Jardine), Vol. 1, pp. 273-299. London, UK: CIRIA/Thomas Telford.

Viggiani, G. \& Atkinson, J. H. (1995). Stiffness of fine-grained soil at very small strains. Géotechnique 45, No. 2, 249-265, http:// dx.doi.org/10.1680/geot.1995.45.2.249.

Wong, P. K. K. \& Mitchell, R. J. (1975). Yielding and plastic flow of sensitive cemented clay. Géotechnique 25, No. 4, 763-782, http://dx.doi.org/10.1680/geot.1975.25.4.763.
Wongsaroj, J. (2005). Three-dimensional finite element analysis of short and long-term ground response to open-face tunnelling in stiff clay. $\mathrm{PhD}$ thesis, University of Cambridge, UK.

Wongsaroj, J., Soga, K. \& Mair, R. J. (2007). Modelling of longterm ground response to tunnelling under St James's Park, London. Géotechnique 57, No. 1, 75-90, http://dx.doi.org/ 10.1680/geot.2007.57.1.75.

Yimsiri, S. (2001). Pre-failure deformation characteristic of soils: Anisotropy and soil fabric. $\mathrm{PhD}$ thesis, University of Cambridge, UK.

Zhao, J., Sheng, D., Rouainia, M. \& Sloan, S. W. (2005). Explicit stress integration of complex soil models. Int. J. Numer. Anal. Methods Geomech. 29, No. 12, 1209-1229. 